\title{
Economics of Conflict: An Overview ${ }^{\dagger}$
}

\author{
Michelle R. Garfinkel \\ University of California, Irvine \\ Stergios Skaperdas \\ University of California, Irvine
}

April 2006

\begin{abstract}
In this chapter, we review the recent literature on conflict and appropriation. Allowing for the possibility of conflict, which amounts to recognizing the possibility that property rights are not perfectly and costlessly enforced, represents a significant departure from the traditional paradigm of economics. The research we emphasize, however, takes an economic perspective. Specifically, it applies conventional optimization techniques and game-theoretic tools to study the allocation of resources among competing activities - productive and otherwise appropriative, such as grabbing the product and wealth of others as well as defending one's own product and wealth. In contrast to other economic activities in which inputs are combined cooperatively through production functions, the inputs to appropriation are combined adversarially through technologies of conflict.

A central objective of this research is to identify the effects of conflict on economic outcomes: the determinants of the distribution of output (or power) and how an individual party's share can be inversely related to its marginal productivity; when settlement in the shadow of conflict and when open conflict can be expected to occur, with longer time horizons capable of inducing conflict instead of settlement; how conflict and appropriation can reduce the appeal of trade; the determinants of alliance formation and the importance of intra-alliance commitments; how dynamic incentives for capital accumulation and innovation are distorted in the presence of conflict; and the role of governance in conflict management.
\end{abstract}

JEL Classification: D30, D70, D72, D74, H56, O17.

Keywords: property rights, enforcement, insecurity, conflict, governance, economic growth, development.

\footnotetext{
$\dagger$ This paper has been prepared for inclusion in T. Sandler and K. Hartley (eds.), Handbook of Defense Economics, Vol. 2 (chapter 3). The authors are grateful to Francisco Gonzalez, Ragnar Torvik and Karl Wärneryd, as well as to the editors of this volume, for their valuable comments on previous drafts. Skaperdas wishes to thank the Center for Global Peace and Conflict Studies and the Center for the Study of Democracy, both at UC Irvine, for financial support.
} 


\section{Introduction}

Conflict is difficult to comprehend from a traditional economic perspective. The difficulty arises from the emphasis that the discipline places on the win-win aspects of exchange and the gains from trade, at the expense of neglecting environments with imperfectly specified and imperfectly enforced property rights. These latter environments are precisely the ones in which conflict typically arises. In this chapter we will review and synthesize recent research that takes an economic perspective to study conflict. This research shares with traditional economics the assumption of self-interested behavior on the part of economic agents. However, contrary to traditional economics, there is no presumption that agents can only produce and trade to make a living. They can also engage in appropriation, grabbing the production of others or defending what they themselves have produced.

Central to the economic analysis of conflict and its consequences, which we emphasize in this chapter, is the tradeoff between production and appropriation. To the best of our knowledge, Haavelmo (1954) was the first economist to model the basic choice between production and appropriation, and did so in a general equilibrium setting. Haavelmo was interested in incorporating appropriation into economic modelling because he thought it was important for understanding economic development. It seems, however, that other scholars in economics did not share his vision. For his work in this area, in sharp contrast to his research in econometrics, has had no discernible impact. Yet, over the past fifteen years or so, we have witnessed a growing research effort, spearheaded largely by Jack Hirshleifer and Herschel Grossman, to try to put "conflict and appropriation" squarely within the scope of discourse and inquiry of the economics discipline, and what we cover in this chapter owes as much to their direct contributions as to their inspiration.

Another important feature of the economic analysis of conflict, which we also emphasize in this chapter, lies in the modelling of conflict as a contest - that is, a game in which participants expend resources on arming so as to increase their probability of winning if conflict were to actually take place. Actual, overt conflict does not necessarily have to occur but arming can be used, as is often in reality, as a bargaining tool and as a deterrent within a larger economic context.

We explore the key ingredient of contests, "contest success functions" or "technologies of conflict" in section 2. These technologies show how probabilities of winning vary with the different levels of arming of those potentially engaged in conflict. For the theory of conflict and appropriation they are the analog of production functions in production theory and utility functions in consumption theory. We discuss the different classes of functional forms that have been used and review their axiomatic foundations or stochastic derivations. 
In section 3 we examine two basic models of conflict, one that involves fighting for an exogenous prize and another in which all production is endogenous and contested by the contending parties. Here we derive some comparative static results of the models in the equilibrium determination of power, to show how allowing for conflict and appropriation can change many of the standard findings from traditional economic theory.

In the subsequent sections, we review a number of advances that have been made recently in this area of research, based largely on variations of one of the two basic models. Section 4 reviews the various factors, such as the destructive effects of war, risk aversion and complementarities in production as well as consumption, that could give adversaries a short-run preference for bargaining and settling instead of fighting. Because commitments are not possible, open conflict can not be ruled out. Hence, settlement takes place in the shadow of conflict. But arming also provides one with a better bargaining position. We show that the bargaining rules in place and the norms shared by the parties to potential conflict are crucial for the level of arming that emerges under settlement.

Although there are many reasons to expect adversaries to settle in the short-run, we often observe open conflict and fighting. Typically, conflict is considered the outcome of incomplete and asymmetric information or, even, a result of misperceptions and irrationality. In section 5, we bring attention to another potentially important hypothesis for the emergence of open conflict. In particular, it seems reasonable to suppose that fighting changes the strategic positions of the adversaries well into the future and in ways that sequential short-run settlements do not. In this case, a party who views the future as being important might choose to fight, despite the short-run benefits of settling. Such a choice would be consistent with rational, forward-looking behavior, based on complete information. If one or more of the parties views the future as being sufficiently important, we would expect the outbreak of war.

Section 6 examines how exchange and trade affect and are affected by insecurity and conflict. When trade across national borders is insecure, but trade within the nation (or autarky) is not, parties may very well choose autarky, even if doing so limits their productive opportunities, because the costs of enforcement under trade are too high. But, in this section we explore, in more detail, the implications of another form of insecuritythat is, where a contested resource can be traded. Trade and autarky in the presence of contested resources generally induce different levels of arming; and, comparing welfare under trade and under autarky is far from being straightforward, for the gains from trade can be outweighed by the additional costs of arming that trade might induce. Thus, the presence of insecurity and conflict can help to explain some types of restrictions on exchange and market interventions that cannot be explained when property rights are 
perfectly and costlessly enforced.

In section 7, we turn to explore some issues that arise when appropriative activities are carried out not by unitary actors, but by individuals organized into groups. We find that, relative to the case where individuals compete on their own for the contested resource, group formation tends to reduce the overall severity of conflict, though that severity varies with different group structures. If we were to assume that groups could somehow commit in advance to a rule to share the prize in case they won, then the severity of conflict would be decreasing in the size of groups, and the grand coalition (a single group consisting of all individuals) would be the efficient structure. But, here we suppose instead that conflicts over the distribution of the prize within groups cannot be resolved so easily. Even factoring in this additional source of conflict, stable group formation reduces the severity of conflict. Nevertheless, as long as there is some cost involved in managing within-group conflict, the grand coalition will generally not emerge as the efficient structure. Whether a structure with larger or smaller groups can be sustained in equilibrium depends crucially on whether groups possess any advantage in managing conflict relative to individuals, and if so to what degree.

Sections 8 and 9 review some dynamic effects of conflict and appropriation, and the role of the state in conflict management. Many of the static inefficiencies we examine in the earlier sections become magnified in dynamic settings, with incentives distorted toward appropriative investment and against innovation. The reduction and management of conflict is briefly reviewed in view of recent research on state organization and institutions. Traditional hierarchical governance tends to reduce internal conflict but displace conflict at a higher, more organized level between autocratic rulers. Modern governance may provide more durable solutions to conflict, yet research about how it functions and interacts with economic growth has essentially only just began. We conclude our overview in section 10 .

\section{Technologies of conflict}

A key ingredient of conflict has been, and still is, the use of weapons: swords, pikes, cannons, bombs, guns, and so on. From an economic perspective, weapons can be thought of as inputs into conflict. However, unlike the case of ordinary economic production, in which inputs are combined cooperatively in order to produce useful output, the inputs of conflict are contributed by each party in an adversarial fashion against other parties. Instead of useful production, the output of conflict can reasonably be thought to be wins and losses. How inputs in conflict - weapons - translate into wins and losses for the different parties involved in conflict is thus the first topic that we examine.

Hirshleifer (1989) was first to call such functions "technologies of conflict," a term 
which we will be using ourselves throughout this chapter. Consider two contending parties, labelled $i=1$ and $i=2$, and denote their choice of weapons as $G_{1}$ and $G_{2}$ (for "guns"). For any given combination of guns, we can expect each party to have a probability of winning and a probability of losing. (The probability of an impasse or "draw" is considered to be zero, but we briefly mention the case when this assumption does not hold below.) Denote the probability of party $i=1$ winning as $p_{1}\left(G_{1}, G_{2}\right)$ and the probability of party $i=2$ winning as $p_{2}\left(G_{1}, G_{2}\right)$.

For $p_{i}\left(G_{1}, G_{2}\right), i=1,2$, to be probabilities, they need to take on values between 0 and 1 and add up to 1 , or equivalently they must satisfy the following: $0 \leq p_{2}\left(G_{1}, G_{2}\right)=1-$ $p_{1}\left(G_{1}, G_{2}\right) \leq 1$. Moreover, we can expect an increase in one party's guns to increase her own winning probability and reduce the winning probability of her opponent; that is, $p_{1}\left(G_{1}, G_{2}\right)$ should be increasing in $G_{1}$ and decreasing in $G_{2}$.

A wide class of technologies that has been examined takes the following additive form:

$$
p_{1}\left(G_{1}, G_{2}\right)=\left\{\begin{array}{cl}
\frac{f\left(G_{1}\right)}{f\left(G_{1}\right)+f\left(G_{2}\right)} & \text { if } \sum_{i=1}^{2} f\left(G_{i}\right)>0 \\
\frac{1}{2} & \text { otherwise }
\end{array}\right.
$$

where $f(\cdot)$ is a non-negative, increasing function. This class has been employed in a number of fields, including in the economics of advertising [Schmalensee (1972)], sports economics [Szymanski (2003)], rent-seeking [Tullock (1980), Nitzan (1994)], and contests in general [see Konrad (2005) for a recent survey]. Luce (1959) axiomatizes such probabilistic choice functions in relation to utility theory, while Skaperdas (1996) provides an axiomatization in relation to contests. Key to both axiomatizations is an Independence of Irrelevant Alternatives property. In the context of conflict, this property requires that the outcome of conflict between any two parties depend only on the amount of guns held by these two parties and not on the amount of guns held by third parties to the conflict.

One unique and appealing feature of the class of conflict technologies in (1) is that it naturally extends to the case of conflict between more than two parties. Thus, if there were $n$ parties to the conflict, denoting the gun choice of party $i$ by $G_{i}$ and the vector of gun choices of all other agents $j \neq i$ by $G_{-i}$, the winning probability of $i$ would be as follows:

$$
p_{i}\left(G_{i}, G_{-i}\right)=\left\{\begin{array}{cl}
\frac{f\left(G_{i}\right)}{\sum_{j=1}^{n} f\left(G_{j}\right)} & \text { if } \sum_{j=1}^{n} f\left(G_{j}\right)>0 \\
\frac{1}{n} & \text { otherwise. }
\end{array}\right.
$$

Although we will touch upon the case of more than two parties in section 7, everywhere else, including in the rest of this section, we will focus on the simple case with $n=2$. 
The most commonly used functional form is the one in which $f\left(G_{i}\right)=G_{i}^{m}$, where $m>0$ (and often, for technical reasons, $m \leq 1$ ), so that

$$
p_{1}\left(G_{1}, G_{2}\right)=\frac{G_{1}^{m}}{G_{1}^{m}+G_{2}^{m}}
$$

Sometimes referred to as the "power form" or as the "ratio form," this functional form is that which was employed by Tullock (1980) and the ensuing voluminous literature on rent-seeking. It is also the workhorse functional form used in the economics of conflict. As Hirshleifer (1989) has noted, the probability of winning in this case depends on the ratio of guns of the two parties, $\frac{G_{1}}{G_{2}}$. To put it differently, this technology of conflict is homogeneous of degree zero in guns. For the general case with arbitrary $n$ parties, $p_{i}\left(t G_{i}, t G_{-i}\right)=p_{i}\left(G_{i}, G_{-i}\right)$ for all $t>0$. This property is rather convenient analytically and largely accounts for the popularity of this functional form in applications, like the Cobb-Douglas form in the case of production functions.

Another well-known functional form is the following "logit" specification, in which $f\left(G_{i}\right)=e^{k G_{i}}$, where $k>0$, so that,

$$
p_{1}\left(G_{1}, G_{2}\right)=\frac{e^{k G_{1}}}{e^{k G_{1}}+e^{k G_{2}}}=\frac{1}{1+e^{k\left(G_{2}-G_{1}\right)}} .
$$

Again as Hirshleifer (1989) has noted and as is evident from the expression above, this specification implies the probability of winning depends on the difference in guns between the two parties. Thus, in general, the probabilities are invariant to the addition of a constant $C$ to the guns of each party-i.e., $p_{i}\left(G_{i}+C, G_{-i}+C\right)=p_{i}\left(G_{i}, G_{-i}\right)$ for all $C$ such that $G_{j}+C>0$ for all $j{ }^{1}$ Though the logit form also has analytical advantages, it has not been used as much as the power form shown in (3). The reason is that, for a number of well-specified models (including the one we examine in 3.1 below, which is analogous to the basic rent-seeking model), no pure-strategy, Nash equilibrium exists.

But, an appealing feature of (4), one that accounts for its popularity in econometric studies of discrete choice, is that it can be derived stochastically. ${ }^{2}$ In particular, suppose each party's "guns" allocation is a noisy predictor of "performance" in battle so that the performance of party $i$ equals $G_{i}+\varepsilon_{i}$, where $\varepsilon_{i}$ is a stochastic error term. If the error term is distributed according to a specific distribution (namely, the extreme value distribution) and the outcome of the battle depends on which party performs best-i.e., $p_{1}\left(G_{1}, G_{2}\right)=\operatorname{Prob}\left\{G_{1}+\varepsilon_{1}>G_{2}+\varepsilon_{2}\right\}$, - then (4) is the resultant functional form.

\footnotetext{
${ }^{1}$ Hirshleifer (1989) as well as section 4 of Hirshleifer (1995b) and Hirshleifer (2000) provide many insightful discussions of the technologies of conflict and comparisons of the functional forms in (3) and (4).

${ }^{2}$ See McFadden (1984) and many econometrics textbooks.
} 
No similar stochastic derivation of the power form in (3) existed, to our knowledge, until Hirshleifer and Riley (1992). On pp. 380-81 of their book, Hirshleifer and Riley include an exercise that asks the reader to prove that the power form in the case of $n=2$ players, as shown in (3) but with $m=1$, can be derived when the performance of party $i$ is now $\theta_{i} G_{i}$, where $\theta_{i}$ is a multiplicative error term with an exponential distributioni.e., $\operatorname{Prob}\left\{\theta_{1} G_{1}>\theta_{2} G_{2}\right\}=\frac{G_{1}}{G_{1}+G_{2}}$. Only recently has this result been extended beyond the case where $m=1$ and $n=2$. In particular, Jia (2005) derives (3) more generally for $m>0$ and $n \geq 2$, assuming that the probability density function for the error, $\theta$ is given by $g(\theta)=a m \theta^{-(m+1)} \exp \left(-a \theta^{-m}\right)$, where $a>0$ and $\theta>0$. Jia shows how $m$ can be interpreted as a "noise" parameter, with a greater value of $m$ inducing less noise in the determination of the winner of a contest. That is, higher values for $m$, and given a certain level of guns for the parties, make for a closer contest. Therefore, from the viewpoint of an adversary, it is cheaper in terms of the cost of guns to increase her probability of winning when $m$ is higher rather than lower. The level of $m$ has been variously identified with "decisiveness" or "effectiveness" of conflict. In the remainder of this chapter, we will be using the latter term.

Thus, both the "power" functional form in (3) and the "logit" form in (4) can be derived axiomatically as well as stochastically. We should mention that the probit function - derived under the assumption $p_{1}\left(G_{1}, G_{2}\right)=\operatorname{Prob}\left\{G_{1}+\varepsilon_{1}>G_{2}+\varepsilon_{2}\right\}$ with $\varepsilon_{i} \quad i=1,2$ normally distributed - has not been used in the literature that we review, most likely because there is no analytical functional form to express it.

The class in (1) and the specific forms in (3) and (4) have the property of symmetry or anonymity, in the sense that only the amount of guns possessed by a party and its adversaries matters for the outcome. Consequently, when two parties hold the same amount of guns, they have equal probabilities of winning and losing. The cost of producing guns might differ across parties, thereby inducing strategic asymmetries between them and resulting in an asymmetric solution for guns (i.e., $G_{1} \neq G_{2}$ ); nevertheless, for each gun held by the parties, the technology of conflict does not favor one party over the other.

There are circumstances, however, in which one party might be favored over another though they hold the same amount of guns. An obvious setting conducive to such an asymmetry is where one party is in a defensive position vis a vis her opponent. The defender typically, but not always, has the advantage. A simple way to extend (1) to admit the possibility of such asymmetries is shown in the following form:

$$
p_{1}\left(G_{1}, G_{2}\right)=\frac{\varphi f\left(G_{1}\right)}{\varphi f\left(G_{1}\right)+(1-\varphi) f\left(G_{2}\right)} .
$$


where $\varphi \in(0,1) \cdot{ }^{3}$ Note that when the parties hold equal amounts of guns, $G_{1}=G_{2}>0$, party $i=1$ 's probability of winning equals $\varphi$ and party $i=2$ 's probability of winning is $1-\varphi$. Thus, when $\varphi>\frac{1}{2}$, party $i=1$ has an advantage, whereas when $\varphi<\frac{1}{2}$ party $i=2$ has the advantage, and the closer $\varphi$ is either to 0 or 1 , the greater is the advantage that one party has over another. Clark and Riis (1998) have axiomatized this asymmetric form for the case of the power function (i.e., where $f(G)=G^{m}$ ), and Grossman and Kim (1995) have employed that form in order to distinguish between offense and defense.

For the technologies of conflict we have reviewed to this point, the sum of the winning probabilities of all parties involved equals 1 . But there are circumstances under which a draw or an impasse might be a reasonable outcome. That is, a battle could very well leave the adversaries in the same relative bargaining position as they were before the battle. Blavatsky (2004) axiomatizes the following reasonable extension of (1) as well as (5), which captures such a possibility:

$$
p_{1}\left(G_{1}, G_{2}\right)=\frac{f_{1}\left(G_{1}\right)}{1+f_{1}\left(G_{1}\right)+f_{2}\left(G_{2}\right)}
$$

where $f_{1}(\cdot)$ and $f_{2}(\cdot)$ are non-negative increasing functions. According to this general formulation, the probability of a draw, given by

$$
1-p_{1}\left(G_{1}, G_{2}\right)-p_{2}\left(G_{1}, G_{2}\right)=\frac{1}{1+f_{1}\left(G_{1}\right)+f_{2}\left(G_{2}\right)},
$$

is always positive. Also note that having $f_{1}(\cdot)=\varphi f(\cdot)$ and $f_{2}(\cdot)=(1-\varphi) f(\cdot)$ yields a straightforward generalization of the asymmetric form in (5). The "1" that appears in the denominator of (6) does not have any special significance, because if we were to multiply the numerator and denominator of (6) by any positive number we would get an equivalent functional form. One way of thinking about (6) is to consider a third party, say "Nature," that has a constant endowment of "guns," $G^{\prime}$, which is defined by $f\left(G^{\prime}\right)=1$ (where $f(\cdot)$ is non-negative and increasing). When Nature "wins", there is a draw. Blavatsky (2004) has extended (6) to more than 2 parties but not in the straightforward way that (2) extends (1).

The technologies of conflict we have reviewed in this section have been derived either axiomatically or stochastically and, thus, are comparable in terms of the foundations to production functions and utility functions. Yet, unlike the case of production functions, to our knowledge there have not been empirical estimates of the technologies of conflict. This is a topic, then, that could be taken up in future research.

\footnotetext{
${ }^{3}$ It would seem arbitrary to assume, along the lines of the specification in (1) that, in this asymmetric case, $p_{i}\left(G_{1}, G_{2}\right)=\frac{1}{2}$ for $i=1,2$, whenever $\sum_{i=1}^{2} f\left(G_{i}\right)=0$. An alternative and more palatable specification would be $p_{1}\left(G_{1}, G_{2}\right)=\varphi$ which would then imply $p_{2}\left(G_{1}, G_{2}\right)=1-p_{1}\left(G_{1}, G_{2}\right)=1-\varphi$.
} 


\section{Representative models of conflict and the determinants of power}

In this section, we present two basic models of conflict, both of which embed the conflict technology presented above into an economic framework of optimizing behavior. This approach to modelling conflict effectively envisions the relations between individual parties as anarchic in the sense that, like sovereign states, there is no higher authority to which they must answer. ${ }^{4}$ Without a higher authority, contracts between parties can be meaningful only if those parties can enforce the contracts themselves. But, since the power of enforcement ultimately derives from the credible threat of using force, under anarchy individual parties cannot write enforceable contracts that would eliminate arming and preclude the use of violence. As these implications indicate, the approach of this research departs sharply from a long tradition in neoclassical economics that largely ignores any imperfections in contracts and views property rights as perfectly and costlessly enforced. However, the approach is much in line with the fundamental assumption of self-interest, for a genuine Homo economicus would not refrain from using force, if by doing so, he could enhance her material well-being.

Laws, institutions and norms would be expected to emerge to limit and shape the use of force by economic agents, as they pursue their self interests. ${ }^{5}$ Nevertheless, under anarchy, an individual's holding of guns would seem paramount in determining her position relative to others and thus in influencing the terms of transactions. Of course, this influence comes at a cost, for the production of guns necessarily diverts valuable resources from other uses and the use of guns can have other more direct negative consequences on welfare.

The model we present in the first subsection abstracts from individual parties' production decisions, and hence might be considered a partial equilibrium framework. Nevertheless, it is closely related to the basic rent-seeking model — see, e.g., Nitzan (1994) and its simplicity allows us to highlight the logic of the interactions between individuals as they contest a given resource. In the subsequent subsection, we present an extended model where the contested pie is endogenous to the decisions that the adversaries make between production and appropriation. This extension shifts the focus of the analysis more squarely on the trade-off between guns and butter, allowing us to make the opportunity cost of guns explicit. Overall, our central objective here is to highlight the implications of abandoning the assumption of neoclassical economic theory that property is secure for (i) the equilibrium determination of income and (ii) the distribution of that income or equivalently, in this model the determination of power.

\footnotetext{
${ }^{4}$ While this research has important implications for the interactions between nations, such interactions are not our primary focus or concern.

${ }^{5}$ See section 4.2.4.
} 


\subsection{Competing for a resource}

Consider an environment populated by two identical, risk-neutral agents. These agents can be thought of as either individuals or collections thereof - for example, tribes or nations. However, we abstract from all problems of collective action and put aside, for now, any issues that may arise with group formation. ${ }^{6}$ Here, we treat each agent as a unitary actor, and suppose that they contest $\bar{R} \equiv 2 R$ units of a resource, which can be consumed directly. Each agent might claim the rights to half or even more of the resource. However, due to imperfect institutions of governance and enforcement, any such claim can be settled only by overt conflict or, equivalently, in this setting under the threat of conflict, through the production of "guns" or "arms" $\left(G_{i}\right)$. In particular, following the approach outlined in section 2 , we model the conflict over $\bar{R}$ as a winnertake-all contest: $p_{i}\left(G_{1}, G_{2}\right)$ denotes the probability that agent $i$ emerges as the winner and thus is able to claim the entire resource $(\bar{R})$ as her prize, leaving nothing for her opponent $j \neq i$ for $i=1,2$. To fix ideas, assume that $p_{i}\left(G_{1}, G_{2}\right)$ is symmetric, taking the functional form shown in (3).

Consistent with the general class of conflict technologies discussed in section 2, this specification implies that agent $i$ 's likelihood of winning the resource $\bar{R}, p_{i}\left(G_{1}, G_{2}\right)$, is increasing in her choice of guns, $G_{i}$, and decreasing in that of her opponent $j \neq i, G_{j}$, for $i=1,2$. Thus, each agent's expected gross winnings, $p_{i}\left(G_{1}, G_{2}\right) \bar{R}$, is similarly increasing in her own production of guns, $G_{i}$ and decreasing in that of her opponent, $G_{j} j \neq i$ for $i=1,2$. However, the production of guns is not costless. In particular, as noted above, producing guns diverts the flow of valuable resources from useful, welfare enhancing activities. ${ }^{7}$ This cost of producing guns is borne by the agent whether or not she wins the contest. Thus, agent $i$ 's expected payoff, $V_{i}\left(G_{1}, G_{2}\right)$, can be written as follows:

$$
V_{i}\left(G_{1}, G_{2}\right)=p_{i}\left(G_{1}, G_{2}\right) \bar{R}-G_{i} \quad i=1,2,
$$

where $p_{i}\left(G_{1}, G_{2}\right)$ is given by (3). Note that under the alternative, non-probabilistic interpretation of (3), where agents are envisioned as dividing the contested resource according to their respective winning probabilities $p_{i}\left(G_{1}, G_{2}\right)$ given their choices of guns, the expected payoff shown above would be equivalent to the agent's ex post payoff. Note further that this interpretation is equivalent to our probabilistic interpretation of (3) as a winner-take-all contest. This equivalence, which arises under various sets of assumptions (including the assumption of risk neutrality specified here), implies, in turn, that the agents are indifferent, in an ex ante sense, between the two contests as a way

\footnotetext{
${ }^{6}$ We take up these issues in section 7 , where we consider the possibility of coalition formation explicitly.

${ }^{7}$ In a more fully articulated setting such as in the model presented in the following section, this opportunity cost could be modelled more explicitly as a reduction in the production of goods available for current consumption and/or for future consumption.
} 
of distributing the resource, $\bar{R}$. However, the actual outcomes and the corresponding payoffs obtained under each could be very different. ${ }^{8}$

Subject to the conflict technology (3) and treating her opponent's choice of guns as given, each agent $i$ chooses $G_{i}$ to maximize her expected payoff (7). The conflict technology implies generally that, if agent $i$ 's opponent were to make no appropriative effort $\left(G_{j}=0, j \neq i\right)$, agent $i$ could seize all of $\bar{R}$ with near certainty by producing an infinitesimally small quantity of guns. But, neither agent would leave such an opportunity unexploited. As such, the "peaceful" outcome where $G_{i}=0$ for $i=1,2$ cannot be an equilibrium outcome, and agent $i$ 's optimizing guns choice satisfies the following first-order condition:

$$
\frac{\partial V_{i}\left(G_{1}, G_{2}\right)}{\partial G_{i}}=\frac{\partial p_{i}\left(G_{1}, G_{2}\right)}{\partial G_{i}} \bar{R}-1=0 \quad i=1,2 .
$$

The first term on the left hand side (RHS) of the condition represents the marginal benefit of guns. By producing an additional gun, holding everything else constant, agent $i$ enhances her chances of winning the prize $(\bar{R})$ or equivalently her power. From (3), it is straightforward to verify that this marginal effect, given $G_{j}>0$, equals

$$
\frac{\partial p_{i}\left(G_{1}, G_{2}\right)}{\partial G_{i}}=\frac{m G_{i}^{m-1} G_{j}^{m}}{\left(G_{1}^{m}+G_{2}^{m}\right)^{2}}, \quad j \neq i, i=1,2 .
$$

The second term on the RHS of (8) represents the marginal cost of guns, a constant and equal to 1 for both players. ${ }^{9}$

Under our specifications for the players' expected payoffs (7) and the conflict technology (3), the first-order conditions shown in (8) combined with (9) for $i=1,2$ define a unique, symmetric pure-strategy (Nash) equilibrium:

$$
G_{i}^{*}=G^{*}=\frac{m}{2} R \quad i=1,2,
$$

implying that each party $i$ has an equal chance of winning $\bar{R}: p_{i}^{*}=p^{*}=\frac{1}{2}$ for $i=1,2 .{ }^{10}$ Thus each player's expected winnings equals $p^{*} \bar{R}=R$, where $R=\frac{1}{2} \bar{R}$ measures the contested resource in per capita terms, as previously defined. But, the players' expected payoffs are also negatively affected by the guns they produce. To be more precise, by

\footnotetext{
${ }^{8}$ Moreover, as discussed in some detail below, the ex ante equivalence breaks down under reasonable conditions, implying a preference for negotiated settlement under the shadow of conflict [see section 4].

${ }^{9}$ It might be more reasonable to suppose that the marginal cost is increasing due to diminishing returns. Although assuming a constant marginal cost of appropriative activity is not critical here, it could matter where, as discussed below, we admit the possibility of group formation. Also see Esteban and Ray (2001).

${ }^{10}$ See Skaperdas and Syropoulos (1997) for conditions and proofs under more general specifications for production.
} 
substituting the solution $G^{*}$ into (7) with $\bar{R}$ replaced by $2 R$, one can verify that the payoff expected by agent $i, V_{i}\left(G^{*}\right)$, in this symmetric equilibrium is given by

$$
V_{i}\left(G^{*}\right)=V^{*}=\left[1-\frac{m}{2}\right] R, \quad i=1,2 .
$$

Since, by assumption, $m \in(0,1]$, this expression shows that each player has an incentive to participate in the contest, even factoring in the cost of producing guns.

One result that follows immediately from these solutions is that a larger "prize," $R$ in per capita terms, induces greater allocations to guns and hence induces more conflict. But, the increased cost of conflict is swamped by an accompanying increase in each side's gross expected winnings. That is, the net effect of an increase in $R$ on each agent's expected payoff is positive, $\frac{d V^{*}}{d R}=1-\frac{m}{2}>0$. The solutions show further that the conflict effectiveness parameter, $m$, has a positive influence on the players' optimizing guns choice, $G^{*}$, and thus a negative influence on the payoff each agent expects to obtain in the symmetric equilibrium, $V\left(G^{*}\right)$. The spill-over effects of the contenders' choices give rise to the possibility that some coordination of choices could make them both better off. In particular, if the two players could enter into a credible agreement to share $\bar{R}$ equally with no the threat of conflict (i.e., without guns, $G^{*}=0$ ), then the payoff to each would be, $V(0)=\frac{1}{2} \bar{R}=R$, implying a gain of $V(0)-V\left(G^{*}\right)=\frac{m}{2} R$, which is precisely the cost of conflict borne by each agent. However, the potential here for mutually beneficial gains is not itself sufficient to induce a better outcome. The critical departure of this research from the long-standing neoclassical approach that rules out the possibility of contracting by agents to eliminate conflict and arming, at the same time, raises important questions about the feasibility of realizing such gains. Below we return to this issue, exploring alternative ways in which agents could possibly limit arming under anarchy.

\subsection{Guns versus butter}

A fundamental premise of the economics literature on conflict is that economic agents often face a tradeoff between producing goods and grabbing what others have produced. Indeed, the tradeoff between production and appropriation is central to the study of interaction between individual parties under anarchy. In this section we extend the model developed above, incorporating production as well as appropriation to study this tradeoff more formally. ${ }^{11}$ This extension enables us to make explicit the opportunity

\footnotetext{
${ }^{11}$ An early form of this model was first presented in Hirshleifer (1988) and can be found in his subsequent publications, including Hirshleifer $(1989,1991,1995 \mathrm{a})$. However, the very first general equilibrium model of this sort appeared in the often neglected work of Haavelmo (1954, pp.91-98). Other contributors to the more recent literature include Garfinkel (1990), Grossman (1991), Skaperdas (1992), Grossman and Kim (1996), Esteban and Ray (1999), Wittman (2000), and Mehlum et al. (2004). Also see Skaperdas (2003) for a detailed review of the literature.
} 
cost of guns and to highlight its role in the determination of the distribution of power between the two agents.

In this model of conflict, each agent $i, i=1,2$, possesses $R_{i}$ units of a secure primary resource. This resource, which can be thought of as a composite of labor and land, cannot be consumed directly. Instead, it is allocated among two sorts of activities: (i) usefully productive activities that eventually yield goods for consumption (i.e., butter) and (ii) appropriative activities that ultimately determine the distribution of those consumption goods among them. To be more precise, each agent $i$ transforms her initial resource $\left(R_{i}\right)$ into guns $\left(G_{i}\right)$ on a one-to-one basis and into an intermediate input $\left(X_{i}\right)$ at a rate of $\beta_{i}$-to-one, as follows:

$$
R_{i}=G_{i}+X_{i} / \beta_{i}, \quad i=1,2
$$

As will become obvious below, $\beta_{i}$ measures agent $i$ 's marginal product in the production of butter. Rearranging (12) shows that her production of $X_{i}$ depends positively on her initial resource, $R_{i}$, net of what she allocates to appropriation, $G_{i}$, as well as positively on the productivity parameter, $\beta_{i}$ :

$$
X_{i}=\beta_{i}\left[R_{i}-G_{i}\right], \quad i=1,2 .
$$

To fix ideas, we suppose henceforth that $\beta_{1} \geq \beta_{2}$. Thus, agent $i=1(i=2)$ is the more (less) productive contender.

Given these allocations, the two sides, $i=1$ and 2 , combine their intermediate inputs, $X_{i}$, in a joint production process that delivers $\bar{B}$ units of butter for consumption, according to the following specification:

$$
\bar{B} \equiv F\left(X_{1}, X_{2}\right)=\sum_{i=1}^{2} \beta_{i}\left[R_{i}-G_{i}\right] .
$$

As we have specified the units and the technology of transformation of the initial resource in (12), the quantity of the intermediate good, $X_{i}$, that agent $i$ contributes to the joint production of butter, $i=1,2$, coincides with the compensation that the agent would receive in a competitive world if property rights were well-defined and perfectly enforced. This hypothetical compensation is increasing in the agent's own marginal product, $\beta_{i}$, as well as that part of her initial resource she chooses to devote to usefully productive activities, $X_{i}=R_{i}-G_{i}{ }^{12}$ [In what follows where there is no risk of confusion, we will

\footnotetext{
${ }^{12}$ One could assume a more general specification for the joint production technology, $F\left(X_{1}, X_{2}\right)$, which is similarly linearly homogeneous and increasing, but is also strictly concave in each input and, exhibits some degree of complementarity between them: $F_{i}>0, F_{i i}<0$, and $F_{i j}>0$ for $j \neq i \quad i=1,2$, where subscripts represent partial derivatives. Skaperdas (1992), Neary (1997), and Skaperdas and Syropoulos
} 
write $F\left(X_{1}, X_{2}\right)$ as $F(G)$ to emphasize the dependence of this function on the agents' gun choices as represented by the vector, $G$, while economizing on notation.]

However, in the anarchic environment we are studying here, the output from the two agents' joint production, $\bar{B} \equiv F(G)$, is subject to dispute, which we suppose is resolved in a winner-take-all contest, with each agent's probability of winning depending on her relative holdings of guns. This method of distributing the yield from their joint efforts in production motivates the agents to devote some of their initial resource to guns production, thereby making the tradeoff between appropriation $(G)$ and useful production $(X)$ embedded in (12) relevant. Specifically, subject to the conflict technology (3) and her production technology (13), each agent $i$ chooses $G_{i}$, taking the other agent's guns choice $\left(G_{j}\right)$ as given, to maximize her expected payoff, which equals the prize that goes to the sole winner -i.e., the aggregate quantity of butter they produce jointlyweighted by the probability that she wins the conflict. Using the specification for total output shown in (14), this expected payoff can be written as

$$
V_{i}\left(G_{1}, G_{2}\right)=p_{i}\left(G_{1}, G_{2}\right) \sum_{k=1}^{2} \beta_{k}\left[R_{i}-G_{j}\right] \quad i=1,2,
$$

where $p_{i}\left(G_{1}, G_{2}\right)$ is given by $(3) .{ }^{13}$

Although the conflict technology (3) implies, as before, that peace (i.e, $G_{1}+G_{2}=0$ ) cannot be a Nash equilibrium outcome, variation in $\beta_{i}$ and $R_{i}$ across agents $i=1$ and 2 means generally that we cannot rule out the possibility that one of the two agents will exhaust all of her initial resource in the production of guns, $G_{i}=R_{i}$, implying that $X_{i}=0$, for $i=1$ or $2 .{ }^{14}$ However, to remain focussed on the central issues of concern, we

(1997) provide such more general treatments of the model presented in this subsection. Here, since the specification for total output shown in (14) assumes that production is separable in the two inputs, $X_{1}$ and $X_{2}$, that representation could be viewed simply as total production which depends on two separate and independent technologies, one for each agent.

${ }^{13}$ Given our assumptions that (i) the players are risk neutral and (ii) the total quantity of production is linearly homogeneous and separable in the two factors, $X_{i}$, our interpretation of conflict as a winnertake-all contest is again equivalent to the non-probabilistic interpretation, which views the winning probabilities as consumption shares. Under the non-probabilistic interpretation, given our separable specification for aggregate production (14), one can think of agent $i$ 's consumption share, $p_{i}\left(G_{1}, G_{2}\right)$, as representing the fraction of her own product, $X_{i}$, that she successfully defends and the fraction of other agent's product, $X_{j}$, that she confiscates with her choice of $G_{i}$, given $G_{j} j \neq i$. [see footnote 12]. For an analysis that distinguishes between defense and offense in appropriation, see Grossman and Kim (1995)

${ }^{14}$ To be sure, given our specifications for the payoff functions (15) and production (14), that a unique, pure-strategy equilibrium exists follows from our specification for the conflict technology (3). In particular, existence requires $p_{i}\left[\partial^{2} p_{i} / \partial G_{i}^{2}\right]<\left(\partial p_{i} / \partial G_{i}\right)^{2}$, and uniqueness of that equilibrium follows from the general characteristics of (1) satisfied by our specification in (3). See Skaperdas and Syropoulos (1997). 
will assume that the following first-order condition is satisfied at an interior optimum:

$$
\frac{\partial V_{i}\left(G_{1}, G_{2}\right)}{\partial G_{i}}=\frac{\partial p_{i}\left(G_{1}, G_{2}\right)}{\partial G_{i}} \sum_{j=1}^{2} \beta_{j}\left[R_{j}-G_{j}\right]-\beta_{i} p_{i}\left(G_{1}, G_{2}\right)=0, \quad i=1,2 .
$$

The first term on the LHS of the condition represents the marginal benefit of guns production, reflecting an increase in the likelihood of winning the contest when agent $i$ produces an additional gun, which is shown in (9). As in the previous model, for both agents, the marginal effect of an increase in their production of guns is multiplied by the contested good to give an expression for the marginal benefit of guns to agent $i$ as a function of the gun choices by both agents. However, in this model, what the agents are contesting-i.e., $\bar{B}=F(G)$-is itself endogenous. The second term on the LHS of the condition represents the marginal cost to the agent of producing that additional gunthat is, the resulting reduction in butter output - weighted by the probability she will win the contest, as only in that case will she realize that (smaller) prize. The marginal cost to each agent $i$ depends positively on her marginal product in the production of $X_{i}$, $\beta_{i}$. At an interior optimum, each agent $i$ balances her marginal cost against her marginal benefit, such that the conditions in (16) implicitly define the equilibrium solutions for guns production, $G_{i}^{*} \in\left(0, R_{i}\right)$, for $i=1,2$.

\subsubsection{Symmetric outcomes}

In the special case where the agents are identical-i.e., $\beta_{i}=\beta=1$ and $R_{i}=R$ for $i=1,2$, - these conditions imply a unique, pure-strategy symmetric Nash equilibrium in which $G_{i}=G^{*}<R$, and consequently each agent has an equal chance of winning the

conflict: $p^{*}=\frac{1}{2}$ for $i=1,2$. To be more precise, using (3) with (16), it is straightforward to verify that

$$
G_{i}^{*}=G^{*}=\frac{m}{m+1} R, \quad i=1,2
$$

which is increasing in the conflict effectiveness parameter $(m)$ as well as in the initial resource $(R)$. In turn, from equation (14), we can find that the agents jointly produce $\bar{B}=F\left(G^{*}\right)=\frac{1}{m+1} 2 R$ units of butter. Then, equation (15) implies that, in this symmetric equilibrium, each agent $i$ obtains an expected payoff, $V_{i}\left(G^{*}\right)$, equal to

$$
V_{i}\left(G^{*}\right)=V^{*}=\frac{1}{m+1} R, \quad i=1,2
$$

which is decreasing in the conflict effectiveness parameter, $m$, but increasing in the initial resource each agent receives, $R$. These are precisely the implications of the simpler model of section 3.1 . 
Even when we relax the symmetry assumption, and suppose instead that $R_{1} \neq R_{2}$, but maintain the assumption that the two agents are equally productive, $\beta_{1}=\beta_{2}=1$, a symmetric equilibrium obtains. That is, letting $\widetilde{R} \equiv \frac{1}{2}\left[R_{1}+R_{2}\right]$ denote the mean value of the two players' initial resource and assuming an interior optimum, ${ }^{15}$ the conditions in (16) imply the following solutions for guns:

$$
G_{i}^{*}=G^{*}=\frac{m}{m+1} \widetilde{R}, \quad i=1,2 .
$$

In this case, since the parties make identical guns allocations $\left(G_{1}^{*}=G_{2}^{*}\right)$ despite the difference in their initial endowments, the agent's expected payoffs, given by

$$
V_{i}\left(G^{*}\right)=V^{*}=\frac{1}{m+1} \widetilde{R}, \quad i=1,2,
$$

are identical, implying that insecurity neutralizes the effects of cross-sectional variation in the resource endowment on individual payoffs. Jack Hirshleifer (1991) attributes this tendency, which he coins the paradox of power, to the relatively poorer side viewing the marginal return from appropriation to be relatively higher than the marginal product from useful production. ${ }^{16}$ Hence, the poorer side tends to devote a relatively greater share of her initial resource to appropriation. This result, however, does not necessarily extend to the more general specification for production, $F\left(X_{1}, X_{2}\right)$, which is similarly linearly homogeneous and increasing, but is also strictly concave in each input [see Skaperdas and Syropoulos (1997)].

\subsubsection{Asymmetric outcomes}

Now suppose that the agents differ with respect to both their initial resources, $R_{i}$, and their marginal products $\beta_{i}$. Suppose, in particular, to fix ideas that $\beta_{1}>\beta_{2}$ such that agent 1 has a comparative advantage in useful production. Assume further that a fully interior optimum exists. ${ }^{17}$ Then taking the ratio of agent $i=1$ 's first-order condition to agent $i=2$ 's first-order condition, using (16) with (9), after some rearranging, shows

$$
G_{2}^{*} / G_{1}^{*}=\left[\beta_{1} / \beta_{2}\right]^{\frac{1}{m+1}}
$$

\footnotetext{
${ }^{15}$ The necessary and sufficient condition for an interior optimum, where neither player exhausts her entire resource on guns production, is the following: if $R_{i}>R_{j}$, then $R_{j}>\frac{m}{2+1} R_{i}$. This condition requires that the difference between the players' initial resource not be too large.

${ }^{16}$ Hirshleifer refers to the case where power (or consumption shares) is equalized across the players having different initial resources as the strong form of the paradox. He also takes note of a weak form in which the disparity in consumption shares is narrower than that in the initial endowments.

${ }^{17}$ As illustrated in the previous example, an interior optimum where $X_{i}>0$ holds for $i=1,2$ requires that any asymmetries present across agents $i$ are relatively mild. In particular, assuming that $R_{i}>R_{j}$, a necessary and sufficient condition for the solutions shown in (23) to hold is that $\left[1+(m+1)\left(\beta_{i} / \beta_{j}\right)^{\frac{m}{m+1}}\right] \beta_{j} R_{j}>m \beta_{i} R_{i}$.
} 
or that $G_{2}^{*}>G_{1}^{*}$ if and only if $\beta_{1}>\beta_{2}$. That is to say, the agent who is less effective in useful production will be the more powerful agent, in the sense that she has the greater chance of emerging as the winner of the conflict to take sole possession of total output, $\bar{B}: p_{1}\left(G_{1}^{*}, G_{2}^{*}\right)<p_{2}\left(G_{1}^{*}, G_{2}^{*}\right)$ or, equivalently, using (21) with (3),

$$
p_{1}^{*} \frac{1}{1+\left(\beta_{1} / \beta_{2}\right)^{\frac{m}{m+1}}}<\frac{1}{2}<1-p_{1}^{*}=p_{2}^{*} \frac{1}{1+\left(\beta_{2} / \beta_{1}\right)^{\frac{m}{m+1}}} .
$$

Further manipulation of the first-order conditions, (16) for $i=1,2$, gives us the following equilibrium solutions for guns,

$$
G_{1}^{*}=\frac{\frac{m}{m+1}\left[\beta_{1} R_{1}+\beta_{2} R_{2}\right]}{\beta_{1}\left[1+\left(\beta_{2} / \beta_{1}\right)^{\frac{m}{m+1}}\right]}<G_{2}^{*}=\frac{\frac{m}{m+1}\left[\beta_{1} R_{1}+\beta_{2} R_{2}\right]}{\beta_{2}\left[1+\left(\beta_{1} / \beta_{2}\right)^{\frac{m}{m+1}}\right]} .
$$

These solutions with the production specification in (14) imply further that the agents' joint production of butter equals $F\left(G^{*}\right)=\frac{1}{m+1}\left[\beta_{1} R_{1}+\beta_{2} R_{2}\right]$. Then, one can easily verify that the payoff expected by agent $i$ in equilibrium, which can be written as $V_{i}\left(G^{*}\right)=$ $p_{i}^{*} F\left(G^{*}\right) i=1,2$, with $p_{i}^{*}$ equal to the appropriate solution shown in (22), is higher for the less productive player, $i=2$, simply because $p_{2}^{*}>p_{1}^{*}$. It is important to note here that, with more general specifications for the production of butter than that assumed here (14), the inequality $\beta_{1}>\beta_{2}$ need not indicate that agent $i=1$ is relatively more productive. Nonetheless, where property is insecure, whoever is relatively more productive will have a smaller chance of enjoying the output she produced with her opponent. ${ }^{18}$

This result might seem surprising at first. After all, it stands in sharp contrast to the prediction of neoclassical economic theory, based on the assumption of well-defined and perfectly and costlessly enforced property rights, that agents are compensated according to their relative marginal productivities. However, the result here is entirely consistent with economic theory. Specifically, it is based on self-interest, as each agent exploits her own comparative advantage. Moreover, although the result has been shown within the context of a simple model, it is quite robust. In particular, it holds for a general class of symmetric conflict technologies, with a more general specification for the production technology than that assumed here. ${ }^{19}$

Equation (21) reveals another striking result of this model, similar to the paradox of power mentioned above. That is, provided the resource constraint in guns production, $R_{i}-G_{i} \geq 0$ or $X_{i} \geq 0$, is not binding, ${ }^{20}$ the equilibrium distribution of power depends

\footnotetext{
${ }^{18}$ For a detailed discussion and analysis which is related to the elasticity of substitution/complementarity between the agents' inputs, see Skaperdas and Syropoulos (1997).

${ }^{19}$ See Skaperdas and Syropoulos (1997). The implications of this result in a dynamic context for incentives to innovate are discussed below in section 8 .

${ }^{20}$ See footnote 17 .
} 
only on the relative value of the players' marginal products $\beta_{i}$ and the conflict effectiveness parameter $m$. The distribution of the initial resource $R_{i}$ across the agents $i=1,2$ plays no role. This finding can be attributed to the combination of two assumptions: (i) the risk neutrality of economic agents; and (ii) the absence of complementarity in production (between input factors) or consumption (between different types of consumption goods). If either of these two assumptions were relaxed, asymmetries in the resource endowment would drive a wedge between the adversaries' guns choices and thus matter for the determination of power. An agent's probability of winning, in this case, would be positively related to the size of her endowment relative to that of her opponent. ${ }^{21}$

The inverse relationship between productivity and power helps us understand an empirical regularity for much of human history: those who enjoyed the highest material rewards also were, or had power over, specialists in violence. Kings, lords, knights, and warriors owed their material standard of living on the coercive power rather than their economic productivity. As Milgrom (1988) and Rajan and Zingales (2000) argue, a similar tendency may well exist within modern organizations in the absence of sufficient restraints on influence activities in such organizations.

Finally, the conflict effectiveness parameter, $m$, has the same qualitative influence in this setting as in the simpler model of the previous section. Specifically, a larger $m$ implies a greater incentive to arm by all agents, and consequently less production of butter and material welfare.

\section{Settlement in the shadow of conflict}

In our presentation to this point, we have not distinguished between conflicts with probabilistic outcomes, in which each contending party has a probability of winning, and conflicts with deterministic outcomes, in which each party receives a share of what is under dispute. The equivalence of the probabilistic and deterministic interpretations of the representative models can be derived under the assumption of risk neutrality. However, risk neutrality is neither sufficient nor necessary. In practice, interactions under anarchy typically involve a great degree of accommodation by the interacting parties with open conflict (or warfare) being only a last resort, and the outcomes under conflict and under settlement are rather different.

To illustrate what sorts of conditions might be more conducive to settlement, where negotiations by the individual parties would be more likely to result in a division of the contested good (a "cold" war) instead of open conflict (a "hot" war), we envision

\footnotetext{
${ }^{21}$ Differences in resource endowments would matter in this case, regardless of whether the players are equally productive $\left(\beta_{1}=\beta_{2}=1\right)$ or not. See Skaperdas and Syropoulos (1997), who provide results in this spirit.
} 
the interactions between the players as a two-stage game with the following protocol of moves:

Stage 1 Parties independently and simultaneously make their guns choices.

Stage 2 Given those choices, they enter into negotiations about how to divide the contested good.

2-1 If they agree on a division, they share the good accordingly.

2-2 If they reach an impasse, their negotiations end in conflict, with the winner taking the entire prize, leaving nothing for the other party.

The decision of whether to fight is made in stage 2. Obviously, both parties would have to agree on a particular division for settlement to emerge as the equilibrium outcome, but only one party has to decide to fight for open conflict to emerge as the outcome. There are a number of compelling reasons for both parties to prefer a settlement in stage 2 , and we discuss briefly some major ones below first. Then we characterize outcomes under settlement under various rules of division.

\subsection{Sources of the preference for settlement}

\subsubsection{Destruction and additional costs of open conflict}

Contrary to our implicit assumption in the models of the previous section, open conflict typically destroys output and resources, and requires the use of arms beyond those that would be necessary for the parties to negotiate a settlement. Under the reasonable assumption that fighting yields no other benefits, a negotiated settlement should be feasible - that is, provided, the parties have open channels of communication.

To illustrate, we return to the benchmark model of section 3.2, where any particular choice of guns that might have been made in stage 1 , say $G_{i}^{\prime} i=1,2$, would, by the technology constraint in (14), result in the following production of butter, $F(G)=$ $\sum_{i=1}^{2} \beta_{i}\left[R_{i}-G_{i}^{\prime}\right]$. We suppose that, in this setting, if fighting were to occur, only a fraction, $\phi<1$, of total butter output, $F(G)$, would be left for the winner with the remaining fraction, $1-\phi$, destroyed in combat. Under settlement, by contrast, this output is divided in accordance with the winning probabilities. Then, given the technology of conflict (1), the expected payoff in the event of open conflict would be $p_{i}\left(G_{1}^{\prime}, G_{2}^{\prime}\right) \phi F(G)$, for $i=1,2$. Under settlement where the losses from fighting are avoided, the agents' payoffs are $p_{i}\left(G_{1}^{\prime}, G_{2}^{\prime}\right) F(G)$ for $i=1,2$. Provided that $\phi<1$, both sides would have an incentive to agree on the division of the total pie in accordance with the winning probabilities. Note that this incentive emerges despite the assumption that the two 
players are risk neutral, suggesting that knowing their attitudes towards risk alone is not sufficient to determine their preference(s) for settlement relative to open conflict.

There would be, of course, many other ways to divide the pie, but the possibilities are limited by each player's option to shut down negotiations and fight instead. That is to say, each agent's expected payoff under open conflict, which depends on their holdings of guns chosen in advance, defines the minimum payoff the agent would be willing to accept under any division rule. At the same time, the agents' holdings of guns serve to enforce any settlement they reach. Hence, the feasibility of these agreements is not predicated on third-party enforcement, and thus could be supported under anarchy. As discussed below in the context of our model with both appropriation and production where the agents are identical, at least one rule of division among the set of rules that could be supported under anarchy (i.e., those rules that both agents find acceptable) strictly dominates the rule of division we have considered which is based on winning probabilities alone. Thus, here we have shown the possibility of a preference for settlement under conditions that are not most favorable to such a preference.

\subsubsection{Risk aversion and the uncertainty of conflict}

The outcome of open conflict is typically subject to much uncertainty. While we have captured this uncertainty in our models, we have, at the same time, maintained that the contending parties are risk-neutral - that they do not care about the risk entailed in the outcome of open conflict. But, the fact of the matter is that most people are risk averse, particularly when it comes to large uncertain events - such as wars - having much potential to affect their their jobs, career paths, health, and more generally their lives. If possible, they would avoid risks, but if it is not possible to avoid these risks, individuals would try to insure against them. We would expect such attitudes toward risk to transfer to political and military leaders and to the risk preferences expressed at the country level. Because war is uncertain but a particular settlement is not, a range of negotiated settlements can be expected to be preferable by both parties.

This logic can be shown within our benchmark model of section 3.2. Again consider any particular choice of guns that might have been made in stage 1 , say $G_{i}^{\prime} i=1,2$. Then the production specification in (14) implies the following total output of butter,

$F(G)=\sum_{i=1}^{2} \beta_{i}\left[R_{i}-G_{i}^{\prime}\right]$. To isolate the importance of risk aversion alone, we assume no destruction from fighting: $\phi=1$. Strictly concave von-Neumann-Morgenstern utility functions-i.e., , $U(\cdot)$ with $U_{B}>0$ and $U_{B B}<0$, where subscripts denote partial derivatives - reflect the agents' aversion to risk. Then, in the event of conflict, agent $i$ 's expected payoff would be $p_{i}\left(G_{1}^{\prime}, G_{2}^{\prime}\right) U[F(G)]+\left[1-p_{i}\left(G_{1}^{\prime}, G_{2}^{\prime}\right)\right] U[0]$. By contrast, under settlement, where each party receives a share of butter that equals her winning 
probability or $p_{i}\left(G_{1}^{\prime}, G_{2}^{\prime}\right) F(G)+\left[1-p_{i}\left(G_{1}^{\prime}, G_{2}^{\prime}\right)\right] 0=p_{i}\left(G_{1}^{\prime}, G_{2}^{\prime}\right) F(G)$, her payoff would be $U\left[p_{i}\left(G_{1}^{\prime}, G_{2}^{\prime}\right) F(G)\right]$. By the strict concavity of $U(\cdot)$, the payoff under settlement is strictly greater than the expected payoff under war for any given set of choices for guns, $G_{1}^{\prime}$ and $G_{2}^{\prime}$. Thus, risk aversion could motivate both sides to agree to a division of the pie according to their winning probabilities whereby they could avoid fighting. ${ }^{22}$

It would be quite reasonable to argue that, in practice, there are multiple sources of uncertainty, whereas we assume only one - who will win and who will lose - with the probabilities $p_{i}\left(G_{1}^{\prime}, G_{2}^{\prime}\right) \quad i=1,2$ known by both sides. Do our results, then, understate the agents' preference for settlement? It is true that assuming only one source of uncertainty imparts quite a bit of knowledge on both parties. It is not immediately obvious, however, that admitting additional sources of uncertainty (e.g., different expectations, unforeseen contingencies, and so on), would make risk averse players even more conservative and more willing to negotiate. To the best of our knowledge, no one has formally examined the effects of risk aversion in such complicated environments. And, there is a well-known finding related to the issue in hand that, in the presence of incomplete information, where each side has a different set of beliefs about the nature of their interaction, the contending sides are more likely to choose open conflict in equilibrium [see, e.g., Brito and Intriligator (1985) and Bester and Wärneryd (2006)]. ${ }^{23}$

\subsubsection{Complementarities in production and consumption}

Another consequence of open conflict having winners and losers is that the distribution of what is being contested among the parties could easily be far from what would be optimal for production or consumption. Consider, for example, the situation where two agents contest some territory. In the case of war, the winner could get all the contested land minus its people who might become refugees on the loser's remaining territory. In this case, the winner would likely have too much land relative to its available labor force, whereas the losing country would have insufficient land relative to its available labor force. In a negotiated settlement, the two countries could avoid this imbalance, thereby making both sides better off than they would be in expected terms under war. Likewise, there are complementarities between final consumption goods and a similar line of reasoning that shows a preference for negotiated settlements applies.

To make this reasoning more explicit, we must consider a slightly different model of conflict. One possibility, which follows our discussion above, involves several modifica-

\footnotetext{
${ }^{22}$ Again, for reasons made explicit below, dividing the pie according to the agents' winning probabilities need not be the best rule, such that the preference for settlement could be stronger than what these calculations would indicate.

${ }^{23}$ Risk aversion can also have distributional effects similar to those examined in the previous section. See Skaperdas (1991) and Konrad and Schlessinger (1997).
} 
tions to the benchmark model presented in section 3.2. In the modified model, the two agents, $i=1,2$, do not contest their output. Instead, as in the model presented in section 3.1, they contest a productive resource, which we denote here by $T$ for territory or land. Let $T_{i}$ denote country $i$ 's holding of land, which would be realized with the outcome of stage 2 of the negotiation process, whether it be under open conflict in a winner-take-all contest or under settlement by a division in accordance with the winning probabilities. At the same time, like the model of section 3.2, this modified model supposes that each agent is endowed with a secure resource, $\widehat{R}_{i}$ units of human capital, which she allocates to appropriative activities $\left(G_{i}\right)$ and productive activities $\left(L_{i}\right)$, subject to the constraint, $\widehat{R}_{i}=G_{i}+L_{i} / \beta_{i}{ }^{24}$ Each agent $i$ produces butter, $B_{i}$, with her inputs $T_{i}$ and $L_{i}$, according to the following technology: $B_{i}=F\left(T_{i}, L_{i}\right) \quad i=1,2$, which is increasing and strictly concave in $T_{i}$ and $L_{i}$ (given $G_{i}$ ) and exhibits some degree of complementarity between its input factors, $F_{T_{i} L_{i}}>0$, where subscripts denote partial derivatives. Now suppose again that in stage 1 , each agent chooses a certain quantity of guns, $G_{i}^{\prime}$, leaving $L_{i}^{\prime}=\beta_{i}\left[\widehat{R}_{i}-G_{i}^{\prime}\right]$ units of labor for the production of butter. Then, under open conflict, agent $i$ 's expected payoff would be $p_{i}\left(G_{1}^{\prime}, G_{2}^{\prime}\right) F\left[T, L_{i}^{\prime}\right]+\left[1-p_{i}\left(G_{1}^{\prime}, L_{i}^{\prime}\right)\right] F\left[0, L_{i}^{\prime}\right]$. Under a negotiated settlement with each party receiving a share of the contested resource equal to her winning probability $T_{i}=p_{i}\left(G_{1}^{\prime}, G_{2}^{\prime}\right) T$, the payoff obtained by each agent $i$ would be $B_{i}=F\left[p_{i}\left(G_{1}^{\prime}, G_{2}^{\prime}\right) T, L_{i}^{\prime}\right]$. While each agent is assumed to be risk neutral, the strict concavity of $F\left(\cdot, L_{i}\right)$ in land makes the players' payoffs under settlement strictly greater than their respective expected payoffs under war for any given choice of guns, $G_{i}^{\prime}$ $i=1,2$.

\subsection{How much arming? Settlement under different rules of division}

Based on a number of alternative two-stage models of conflict-largely, variations of the benchmark model presented in section 3.2-with the protocol of moves specified above, we have shown there exists a range of different scenarios that render settlement preferable to open conflict. Settlement would then be a part of any perfect equilibrium of games with the protocol of moves that we specified above. However, we have not even touched upon the implications of settlement for arming. Recall that, in this anarchic setting, the individual parties can make no firm commitments regarding their guns choices. Does the expectation of reaching a negotiated settlement in the future reduce the parties'

\footnotetext{
${ }^{24}$ It is important to distinguish not only between secure and insecure resource endowments, but given our interest here in complements in production, also between different types of factor inputs. Hence, whereas we view the secure resource, $R$, in the model of section 3.2 as a composite of labor, land, capital and other inputs, we must view the secure resource $\widehat{R}$ of this modified framework more narrowly to exclude land, the insecure resource. That all land is insecure in this modified framework is not important for our purposes. But, if we were to relax this assumption, the quantity of agent $i$ 's secure land would be included in the measure $T_{i}$.
} 
choices relative to the case where they anticipate war? Furthermore, among the many possible negotiated settlements and rules of division that would be acceptable to both sides, which ones would the two sides be expected to use? Are there any rules of division that are "better" than others and, if so, in what sense? While we cannot answer all of these questions, in this subsection we illustrate how different rules of division affect arming and material welfare. In particular, we demonstrate the sensitivity of arming and welfare to the rule of division.

To proceed, we return to the benchmark model of section 3.2, with one modification only, that open conflict is destructive. ${ }^{25}$ Specifically, suppose that a fraction $1-\phi$ of butter would be lost if fighting broke out. Assume further, for convenience, that both agents are identical with respect to their productivities: $\beta_{1}=\beta_{2}=1$. We continue, however, to allow for differences in their initial resource: $R_{1}$ and $R_{2}$, with $\widetilde{R} \equiv \frac{1}{2}\left[R_{1}+R_{2}\right]$ indicating the mean value. If open conflict were to break out in the second stage, the two parties' guns choices, indicated by the vector $G$, and the resulting production of butter, $\bar{B}=F(G)$, as dictated by (12) and (14) when $\beta_{i}=1$ imply that the expected payoff for agent $i=1,2$ would be given by the total quantity of butter not destroyed in combat weighted by the probability of winning, $p_{i}\left(G_{1}, G_{2}\right)$, as specified in (3):

$$
V_{i}^{w}=p_{i}\left(G_{1}, G_{2}\right) \phi\left[2 \widetilde{R}-G_{1}-G_{2}\right]
$$

for $i=1,2$.

Under settlement, the two sides agree to divide their joint product, $\bar{B}=F(G)$, according to some rule, which will depend at least in part on their guns choices. For now, suppose that, by this rule, the share of total butter agent $i$ receives is $\delta_{i}\left(G_{1}, G_{2}\right)$, implying the following payoff under settlement:

$$
V_{i}^{s}=\delta_{i}\left(G_{1}, G_{2}\right)\left[2 \widetilde{R}-G_{1}-G_{2}\right],
$$

for $i=1,2$.

\subsubsection{Equilibrium under open conflict}

For future comparisons, consider the outcome if both agents expect their negotiations to breakdown, resulting in open conflict in stage 2 . With this expectation, each agent $i$ would choose $G_{i}$ in stage 1 to maximize her expected payoff, $V_{i}^{w}$, subject to the conflict

\footnotetext{
${ }^{25}$ As suggested by our discussion above, either risk aversion or complementarity in production or consumption would similarly create a short-term incentive for the parties to settle. Assuming that open conflict has a destructive element, however, makes the calculus much easier. For a comparison of alternative rules of division in the case of complementarities, see Anbarci et al. (2002).
} 
technology (3), taking the other side's choice as given. The first-order conditions from the agents' optimization problems, assuming an interior optimum, are given by

$$
\frac{\partial V_{i}^{w}}{\partial G_{i}}=\frac{\partial p_{i}\left(G_{1}, G_{2}\right)}{\partial G_{i}} \phi\left[2 \widetilde{R}-G_{1}-G_{2}\right]-\phi p_{i}\left(G_{1}, G_{2}\right)=0, \quad i=1,2 .
$$

Observe that $\phi>0$ can be factored out from both the first term - the marginal benefit of guns - and the second term - the marginal cost of guns - on the LHS of each agent's condition. Thus, the conditions above for $i=1,2$ simplify to those from the model of section 3.2 (16), with $\beta_{1}=\beta_{2}=1$. As can be easily confirmed using the conditions above with (3) and (9), the optimizing solutions, $G_{i}^{w}$, are given by

$$
G_{i}^{w}=G^{w}=\frac{m}{m+1} \widetilde{R}, \quad i=1,2,
$$

and are identical to those where war was assumed not to be destructive (19). ${ }^{26}$ These solutions, in turn, imply an equal distribution of power: $p^{w}=\frac{1}{2}$ for $i=1,2$. Then combining equations (26) and (14) shows that the quantity of butter available for consumption, after factoring in the destruction of warfare, would be $\phi F\left(G^{w}\right)=\frac{2 \phi}{m+1} \widetilde{R}$. Thus, the payoff that each party $i$ could expect under war, $V_{i}^{w}$, is

$$
V_{i}^{w}=V^{w}=\frac{\phi}{m+1} \widetilde{R}, \quad i=1,2,
$$

which is decreasing in war's destruction $(1-\phi>0)$ and the effectiveness of conflict $(m)$, but increasing in the mean value of the initial resource $\left(\widetilde{R} \equiv \frac{1}{2}\left[R_{1}+R_{2}\right]\right)$.

\subsubsection{Equilibrium under settlement: Division by winning probabilities}

Now we suppose that both sides expect that they will be able to agree in stage 2 on a division of total output according to their winning probabilities: $\delta_{i}\left(G_{1}, G_{2}\right)=p_{i}\left(G_{1}, G_{2}\right)$, as specified in (3). Given that expectation, each party $i$ in stage 1 chooses $G_{i}$ to maximize $V_{i}^{s}$ subject to (3) taking the other agent's choice as given. The associated first-order conditions, in this case given by,

$$
\frac{\partial V_{i}^{p s}}{\partial G_{i}}=\frac{\partial p_{i}\left(G_{1}, G_{2}\right)}{\partial G_{i}}\left[2 \widetilde{R}-G_{1}-G_{2}\right]-p_{i}\left(G_{1}, G_{2}\right)=0, \quad i=1,2,
$$

are identical to those in the case where war is anticipated, since $\phi$ drops out of the latter expressions, implying that the optimizing guns choices, denoted by $G_{i}^{p s} i=1,2$ in this case, are identical to the optimizing choices when open conflict is anticipated in stage 2 : $G^{p s}=G^{w}$ as shown in (26).

\footnotetext{
${ }^{26}$ Thus, the condition for an interior optimum when war is destructive is identical to the condition which abstracts from war's destructive effects [see footnote 15].
} 
This result should not be surprising. Given risk neutrality and the separability of production in its inputs, $X_{i} i=1,2$, the marginal benefit of guns relative to their marginal cost under settlement with this rule of division, $\delta_{i}\left(G_{1}, G_{2}\right)=p_{i}\left(G_{1}, G_{2}\right)$, is identical to that under open conflict. With the incentive structure unchanged at the margin, both sides naturally allocate the same amount of resources to guns as they would under conflict, whereby each can ensure that her opponent gains no advantage in her bargaining position for their negotiations relative to their respective positions of power if they were to wage war. As a consequence, the quantity of intermediate goods each brings to the joint production process under settlement is identical to that under war, and the total amount of butter produced is also unchanged.

However, the equivalence of the players' allocation to guns when war is anticipated to that when settlement is anticipated should not be interpreted as an indication of the irrelevance of the damaging effects of warfare. Those effects do matter, as reflected in the difference between the size of total pie to be divided under settlement, $F\left(G^{p s}\right)$, and the size the pie contested under open conflict, $\phi F\left(G^{w}\right)$, given by $F\left(G^{p s}\right)-\phi F\left(G^{w}\right)=$ $\frac{2(1-\phi)}{m+1} \widetilde{R}$, which is positive by our assumption that war is destructive, $1-\phi>0$. Although the way in which the agents divide the pie under settlement coincides with that under open conflict ( $p^{p s}=p^{w}=\frac{1}{2}$ for $i=1,2$ ), by allowing the agents to avoid the destructive effects of open conflict, settlement with $\delta_{i}\left(G_{1}, G_{2}\right)=p_{i}\left(G_{1}, G_{2}\right)$ brings both sides a higher payoff, $V_{i}^{p s}$, given by

$$
V_{i}^{p s}=V^{p s}=\frac{1}{m+1} \widetilde{R}, \quad i=1,2,
$$

which exceeds that which they could expect under war, $V^{w}$, as shown in (27). The difference, given by $\frac{1}{2}\left[F\left(G^{p s}\right)-\phi F\left(G^{w}\right)\right]$ is positive, as argued above, and increasing in the mean value of the initial resource, $\widetilde{R}$ as well as war's destructive effects on output, $1-\phi$, but decreasing in the effectiveness of conflict, $m$. The negative effect of $m$ can be attributed to its equally negative influence on butter production under settlement and under war which is only in the latter case subject to destruction.

\subsubsection{Equilibrium under settlement: Split-the-surplus rule of division}

Still, one has to wonder if it would be possible for the agents to settle on a division of their joint product without diverting as many resources to the production of guns. One alternative division splits the surplus realized relative to the threat point of war equally; hence, it should not be surprising that this rule is referred to as split-the-surplus. Under risk neutrality, this rule coincides with the prescription of any symmetric bargaining solution, including the Nash bargaining solution, and is implementable non-cooperatively by a number of alternating-offers games [see Mutthoo (1999) or Osborne and Rubinstein 
(1990)]. This rule can be found by simply setting $V_{1}^{s}-V_{1}^{w}=V_{2}^{s}-V_{2}^{w}$ for any given $G_{1}, G_{2}$, where $p_{1}\left(G_{1}, G_{2}\right)=p\left(G_{1}, G_{2}\right), p_{2}\left(G_{1}, G_{2}\right)=1-p\left(G_{1}, G_{2}\right), \delta_{1}\left(G_{1}, G_{2}\right)=\delta\left(G_{1}, G_{2}\right)$ and $\delta_{2}\left(G_{1}, G_{2}\right)=1-\delta\left(G_{1}, G_{2}\right)$ :

$$
\delta\left(G_{1}, G_{2}\right)=\phi p\left(G_{1}, G_{2}\right)+\frac{1}{2}(1-\phi) .
$$

We continue to use the power functional form shown in (3). Each party's share of total output under settlement, $\delta$ for agent $i=1$ and $1-\delta$ for agent $i=2$, is a weighted combination of two possible rules:

(i) the probabilistic contest success function, $p\left(G_{1}, G_{2}\right)$; and,

(ii) a 50-50 split of the output outright.

The relative weights are determined by the destruction parameter $1-\phi$. When $\phi$ is smaller implying that more output is destroyed in warfare, the conflict technology plays a smaller role in the determination of the distribution of final output, and each side's choice of guns has a smaller impact on the settlement outcome.

The agents' optimizing choices for guns made in stage 1 , when they anticipate that they will agree in the second stage to divide their joint product based on (29), will again be symmetric, but not identical to their choices when they anticipate open conflict (or equivalently to their choices when they anticipate settlement where their joint product is divided according to their respective winning probabilities). In particular, from the first-order conditions to the optimization problems for agents $i=1,2$, given respectively in this case by,

$$
\begin{aligned}
& \frac{\partial V_{1}^{s s}}{\partial G_{1}}=\frac{\partial p\left(G_{1}, G_{2}\right)}{\partial G_{1}} \phi\left[2 \widetilde{R}-G_{1}-G_{2}\right]-\delta\left(G_{1}, G_{2}\right)=0 \\
& \frac{\partial V_{2}^{s s}}{\partial G_{2}}=-\frac{\partial p\left(G_{1}, G_{2}\right)}{\partial G_{2}} \phi\left[2 \widetilde{R}-G_{1}-G_{2}\right]-\left[1-\delta\left(G_{1}, G_{2}\right)\right]=0,
\end{aligned}
$$

with $\delta\left(G_{1}, G_{2}\right)$ specified in (29), using (3) and (9), one can find the agents' allocations to guns in the symmetric equilibrium, denoted by $G_{i}^{s s}$ :

$$
G_{i}^{s s}=G^{s s}=\frac{\phi m}{\phi m+1} \widetilde{R}, \quad i=1,2 .
$$

Since $\phi<1$, the allocation to guns under settlement with this rule is less than that under war: $G^{s s}<G^{p s}=G^{w}$. The smaller role played by the agents' guns choices in the split-the-surplus rule of division induces less equilibrium arming than that which would emerge either under open conflict or under settlement where $\delta_{i}=p_{i}$. Furthermore, as war becomes more destructive (i.e., as $\phi$ decreases), the importance of guns in $\delta\left(G_{1}, G_{2}\right)$ 
falls further, and, as a consequence, so does the equilibrium allocation to guns. Since the two agents produce the same quantity of guns, $p^{s s}=1-p^{s s}=\frac{1}{2}$, implying each is positioned to secure one-half of total output in their negotiations: $\delta=1-\delta=\frac{1}{2}$. With the production specification shown in (14), the agents' guns choices give us total output, $F\left(G^{s s}\right)=\frac{2}{\phi m+1} \widetilde{R}$, which exceeds that under war, $F\left(G^{w}\right)$, again provided that conflict is destructive $(1-\phi>0)$. This solution for output and its division according to $\delta=\frac{1}{2}$ implies that, under settlement with the split-the-surplus rule of division, party $i$ can obtain a payoff, $V_{i}^{s s}$, equal to

$$
V_{i}^{s s}=V^{s s}=\frac{1}{\phi m+1} \widetilde{R} \quad i=1,2,
$$

which is strictly greater than $V^{p s}$ as well as $V^{w}$. The potential short-term gain from settlement in this case, given by $V^{s s}-V^{w}=\frac{m(1-\phi)}{(m+1)(\phi m+1)} \widetilde{R}$, is increasing in the mean value of the initial resource $(\widetilde{R})$ and in war's destructive element, $1-\phi$, as before, but also increasing in the effectiveness of conflict $(m)$. The positive influence of $m$ can be attributed to the reduction in the players' incentive to arm under this particular rule of division given any $m$ relative to the case of open conflict. That is, butter production is less sensitive to an increase in $m$ under settlement than it is under open conflict. Although production under conflict and settlement both fall with $m$ increases, any given increase in $m$ causes $F\left(G^{s s}\right)$ to fall by less than $F\left(G^{w}\right)$, thereby augmenting the possible gains under settlement.

\subsubsection{Discussion: Rules of division and norms of conduct}

There are a variety of other rules which differ with respect to their sensitivity to the agents' guns choices. In another, more complex environment, similar to that sketched above in section 4.1.3, Anbarci et al. (2002) examine the sensitivity of the parties' arming choices to rules of division under settlement generated by three alternative bargaining solution concepts. In their analysis, they find that the extent to which a rule depends on the players' threats points (i.e., their expected payoffs under conflict) has a positive influence on the extent to which the rule induces guns production under settlement, while leaving their relative bargaining positions unaffected, and thus has a negative effect on the players' payoffs. ${ }^{27}$ Their findings suggest a positive role for norms against threats

\footnotetext{
${ }^{27}$ The rules analyzed include: (i) the split-the-surplus rule when there are cardinal preferences; (ii) the equal-sacrifice rule which splits the difference between the players' maximum, feasible payoffs and their respective payoffs under conflict; and, (iii) the Kalai-Smorodinsky rule which is effectively a weighted average of the first two rules. Among those rules, the equal-sacrifice rule induces the smallest amount of guns production, while the the split-the-surplus rule falls at the other end of the spectrum, and the Kalai-Smorodinsky rule lies in between the two extremes. Anbarci et. al. (2002) suggest that these tendencies remain intact as we move away from the symmetric case, as long as the differences do not
} 
in anarchic settings. In particular, such norms can influence the conduct of the players in such a way so as to lower their incentive to arm, without substantively changing the terms of the settlement, thereby enhancing material welfare, even in the absence of a higher authority. Other norms and institutions similarly limit arming under anarchy, though we would not expect that they could substitute fully for guns. Guns will always be around, for they provide the "last-resort" means of conveying a credible threat to use force when all else fails. But arming could be supplanted, to a large extent, by diplomacy and politics, provided that the norms, institutions, and organizations are widely recognized as relevant to settling disputes.

In a related strand of the literature that can be traced back to Axelrod (1984), social scientists have modelled the evolution of norms, institutions and organizations as cooperative equilibria of indefinitely repeated supergames. In such games, the more individual parties value the future, the larger is the set of feasible outcomes (i.e., those which can be supported under anarchy), as alternatives preferred by all interested parties over open conflict. This approach, which exploits the repeated game setting with a dynamic strategy, could provide the rationale for the adoption of rules or norms that call for lower spending on guns, thereby leaving more resources for the production of butter. ${ }^{28}$ However, Powell (1993) and Skaperdas and Syropoulos (1996a) have found, in different settings, that a longer shadow of the future could add to the players' incentive to arm under conflict. Moreover, as we shall see in the next section, a longer shadow of the future could reverse their preference ordering of settlement and war, to favor war.

\section{Why fight?}

Given our discussion identifying a wide variety of factors that tend to create a shortterm preference for settlement over open conflict, the emergence of inter-state and civil wars throughout history might seem puzzling. In what follows, we outline some of the longstanding and the more recent explanations for why we observe open conflict.

\subsection{Traditional explanations: Asymmetric information, misperceptions, ir- rationality}

War is often attributed to misperceptions, misunderstandings, or simply to irrationality and base instincts. But, those seeking a explanation consistent with rational behavior

grow too large. In our simple setting, where the Pareto frontier is linear, all division rules yield the same solution.

${ }^{28}$ Garfinkel (1990) shows how, for a given rule of division, the set can be restricted by exogenous factors - namely, the mean and variance of the distribution from which the players' initial resource endowments are (identically) drawn. A larger mean increases whereas a mean-preserving spread reduces that set. 
often appeal instead to the sorts of problems that can arise under asymmetric information, where the parties involved are assumed to know more about themselves in terms of their own valuation over what is being disputed and its willingness to bear the risks of war to fight for it as well as the strength of their own military forces than do their opponents. If the parties could communicate their privately held and otherwise unverifiable information to the opponent credibly during the bargaining process, they could facilitate a peaceful settlement. As discussed above, such an outcome would be preferable to open conflict. However, there are incentives to misrepresent that information. Specifically, each party would like to appear "tougher" than they truly are - not only in terms of their resolve to fight, but in terms of the strength of their military forces as well - to obtain a more advantageous position in the negotiations. Thus, any attempt to reveal this private information say through verbal communication is not likely to be very successful. But, Brito and Intriligator (1985) show in their seminal work that war can emerge in a separating equilibrium as a costly means of communication. Fearon (1995) suggests along similar lines that, in settings of asymmetric information, war could be chosen by a country, in a preemptive move, as a costly signal of its strength to others it may encounter in future negotiations. Sánchez-Pagés (2004) extends this line of reasoning to suppose that information about the adversaries' strength can be transmitted on the battlefield in limited conflict before and during negotiations until a final settlement is reached or negotiations breakdown, resulting in a full scale war. Azam and Mesnard (2003) and Bester and Wärneryd (2006) identify conditions under which, given asymmetric information, a peaceful agreement is not possible. ${ }^{29}$

\subsection{Incomplete contracting in the shadow of the future}

War can be rationalized, however, without appealing to problems of information at all. This alternative explanation, which has been proposed and examined recently by Fearon (1995), Powell (2006), and ourselves in Garfinkel and Skaperdas (2000), has two key components:

(i) Although short-term contracts, conditional on arming and under the threat of conflict, can be written, adversaries are unable to enforce long-term contracts on arming.

(ii) Open conflict changes the future strategic positions of the adversaries in different

\footnotetext{
${ }^{29}$ To be sure, there are circumstances where asymmetric information could alleviate conflict. In particular, Wärneryd (2003) shows that, if both parties are equally informed about the value of the prize they are contesting, the conflict between them can be more intense, thereby inducing more arming in equilibrium, than one would observe if only one of the two parties were fully informed about the value of the prize.
} 
ways than a peaceful contract under the threat of conflict does.

To illustrate, we extend the one-period model of section 3.1 to two periods, with period $t=1$ representing today and period $t=2$ representing the future, and assume that war is destructive, $\phi<1 .^{30}$ At the beginning of each of the two periods $t=1,2$, there are $\bar{R}=2 R$ units of a resource which can be consumed directly. The sequence of actions within each period is as specified in the previous section: In the first stage of period $t$, each side makes its guns choice; and, in the second stage of period $t$, given their choices of guns $G_{i t}$ for $i=1,2$, they decide whether to settle on a division of the resource, $\bar{R}$, or to go to war. We assume that, under settlement, the resource is divided in accordance with (29), which splits the surplus equally. ${ }^{31}$ In the event of a war in $t=1$, the winning party alone takes possession of the contested resource net of the war's destructive effects, $\phi \bar{R}$, for consumption, leaving nothing for the losing party. We assume further to emphasize war's longer term effects in the most convenient way, that the losing party is eliminated all together in the future. ${ }^{32}$ In this case, the winning party is able to enjoy, on top of today's resource endowment, the future endowment, without any sort of conflict and, thus, without any need to arm. ${ }^{33}$ However, both the current and future resource endowments are subject to the destructive forces of a war in the current period.

In this dynamic setting, actions taken in both stages of period $t=1$ influence the amount of resources available to them in period $t=2$. Rational, forward-looking parties will take this influence into account when making their period $t=1$ choices. But, to do so, they need to know what would occur in period $t=2$ for each possible outcome (war and settlement) in period $t=1$. This perspective accords with the notion of sub-game

\footnotetext{
${ }^{30}$ In Garfinkel and Skaperdas (2000), we develop this argument within the context of the model of appropriation and production presented above in 3.2. In other related research, McBride and Skaperdas (2005) examine an infinite-horizon version of the model presented here, modified to allow for the possibility that the final winner of the conflict will have to win multiple battles. Based on related finite and infinite horizon models, Bester and Konrad (2004, 2005) extend the scope of the analysis to examine the effect of asymmetries between the rivals who contemplate whether or not to attack specific territories.

${ }^{31}$ In cases where the players are risk neutral and the opportunity cost of guns is constant such that the Pareto frontier is linear, all symmetric axiomatic bargaining solutions prescribe the same outcome, which is precisely that which is given by this rule.

${ }^{32}$ In a more general setting such as that of Skaperdas and Syropoulos (1997) where there is production and the production technology exhibits diminishing returns and complementarity in the two parties' inputs, the qualitative results of this logic would follow through with a less extreme assumption. All that would be required is that the defeated side's second-period initial resource is sufficiently small relative to that of the victor in the case of open conflict.

${ }^{33}$ Strictly speaking, the contest success function specified in (3) requires that the remaining party devote some resources to arming. However, it need only devote an infinitesimal amount to guns to gain full possession of $\phi \bar{R}$. But, to keep matters simple, we suppose that a party who receives nothing in the first period simply cannot participate in the second period of the game.
} 
perfection, an appropriate equilibrium concept for such dynamic games. We therefore solve the model backwards, starting from the second and final period.

\subsubsection{Preliminaries: The second-period outcome}

In the second and final period of the game, neither side has to consider the effects of their choices for the future; there is no future beyond that period. Hence, the conditions and constraints effective in the second period are identical to those in the single-period model.

WHEN THERE IS SETTLEMENT IN THE FIRST PERIOD. When neither side has been eliminated by a war in period $t=1$, the choices they face in period $t=2$ will be identical to those within the context of a one-period model. That is, as confirmed below, the destruction caused by war creates a short-term preference for settlement. Accordingly, party $i$ 's choice of guns maximizes $V_{i 2}\left(G_{1}, G_{2}\right)=\delta_{i}\left(G_{1}, G_{2}\right) \bar{R}-G_{i}, i=1,2$, where $\delta_{1}\left(G_{1}, G_{2}\right)$ is given by $(29)$ and $\delta_{2}\left(G_{1}, G_{2}\right)=1-\delta_{1}\left(G_{1}, G_{2}\right)$. As can be easily verified, the solutions for guns are

$$
G_{12}^{s}=G_{22}^{s}=\frac{\phi m}{2} R
$$

where as previously defined $R$ measures the contested resource in per capita terms. This expression reveals that the optimizing choice for guns is increasing in the conflict

effectiveness parameter, $m$, and the contested resource $R=\frac{1}{2} \bar{R}$. In addition, since the relevance of each player's guns choices for determining its respective share of the contested resource, by the specification of the division rule (29), is negatively related to the destructiveness of war, $-\phi$, guns production under settlement too is negatively related to $-\phi$. In fact, given the destructive effects of war $(\phi<1)$, the solution for guns under settlement with the split-of-surplus division rule (29) in this model, as in the model of section 3.2 with production and appropriation, is less than that under war [see equation (10)].

Since $G_{12}^{s}=G_{22}^{s}$, each party gets an equal share of the contested resource, $\delta=1-\delta=$ $\frac{1}{2}$, which implies the following period $t=2$ payoffs:

$$
V_{12}=V_{22}=\left[1-\frac{\phi m}{2}\right] R,
$$

which for $\phi<1$ is greater than the payoff each side expects under conflict (11). Thus, as claimed above, the short-term preference for settlement is present in this model too when war is destructive.

WHEN THERE IS WAR IN THE FIRST PERIOD. Now when there is war in period $t=1$, the winning party need not allocate any valuable resources to arming in period $t=2$ to 
ensure a share of the resource, since by assumption the loser is eliminated, with a zero payoff. In eliminating the opponent, the winning party can avoid the period $t=2$ cost of conflict. Still, the destructive effect of combat in period $t=1$ carries over into period $t=2$, such that there are only $\phi \bar{R}=\phi 2 R$ units of the endowment (where $\phi<1$ ) left for the winner to enjoy. These assumptions are summarized as follows: given that war breaks out in period $t=1$, no choices are made in period $t=2$ and the payoffs are given by:

$$
V_{i 2}=\left\{\begin{array}{cl}
\phi 2 R & \text { if } i \text { wins the war } \\
0 & \text { otherwise }
\end{array}\right.
$$

for $i=1,2$. In this case, either $V_{12}>0$ and $V_{22}=0$ or $V_{12}=0$ and $V_{22}>0$.

\subsubsection{Settlement or war? First-period choices}

In the first period, each party cares about the sum of the payoffs it will receive over the two periods. That is, party $i$ 's two-period objective function is described by:

$$
W_{i}=V_{i 1}+\lambda V_{i 2}
$$

for $i=1,2$ where $\lambda \in(0,1]$ represents the players' identical time preference. As revealed by equations (33) and (34), the second-period payoffs depend on first-period choices in a discrete way. In effect, then, the two-period payoffs, $W_{i}$, depend on what occurs in the first period only - that is, on the party's first-period arming and war-or-settlement decisions.

WHEN THERE IS WAR. Using (34) and (35) and letting $p\left(G_{11}, G_{21}\right)$ denote side 1's probability of winning in period $t=1$ and $1-p\left(G_{11}, G_{21}\right)$ denote side 2's probability of winning in period $t=1$, the war payoffs, given $G_{i 1} i=1,2$, are:

$$
\begin{aligned}
W_{1}^{w} & =p\left(G_{11}, G_{21}\right) \phi 2 R-G_{11}+\lambda p\left(G_{11}, G_{21}\right) \phi 2 R \\
& =p\left(G_{11}, G_{21}\right) \phi(1+\lambda) \bar{R}-G_{11}, \\
W_{2}^{w} & =\left(1-p\left(G_{11}, G_{21}\right)\right) \phi 2 R-G_{21}+\left(1-p\left(G_{11}, G_{21}\right)\right) \lambda \phi 2 R \\
& =\left(1-p\left(G_{11}, G_{21}\right)\right) \phi(1+\lambda) \bar{R}-G_{21} .
\end{aligned}
$$

Keep in mind that these are expected payoffs: the winnings realized by party $i$ in the event of a victory in the period $t=1$ war, compounded over the two periods and weighted by the party's probability of winning.

When there is Settlement. As before, let $\delta\left(G_{11}, G_{21}\right) \in(0,1)$ denote the share received by side 1 and thus $1-\delta\left(G_{11}, G_{21}\right)$ denote the share received by side 2 in stage 
2 of the first period, given $G_{i 1}$ for $i=1,2$ and the sharing rule negotiated in the second period under settlement. ${ }^{34}$ Then, the two-period payoffs under settlement, using (33) and (35), can be written as

$$
\begin{aligned}
W_{1}^{s} & =\delta\left(G_{11}, G_{21}\right) 2 R-G_{11}+\lambda\left[1-\frac{\phi m}{2}\right] R \\
& =\left[\delta\left(G_{11}, G_{21}\right)+\frac{\lambda}{2}\left(1-\frac{\phi m}{2}\right)\right] \bar{R}-G_{11}, \\
W_{2}^{s} & =\left(1-\delta\left(G_{11}, G_{21}\right)\right) 2 R-G_{21}+\lambda\left[1-\frac{\phi m}{2}\right] R \\
& =\left[1-\delta\left(G_{11}, G_{21}\right)+\frac{\lambda}{2}\left(1-\frac{\phi m}{2}\right)\right] \bar{R}-G_{21} .
\end{aligned}
$$

In contrast to the two-period payoffs under war (36a) and (36b), these payoffs are certain.

For any given combination of guns $\left(G_{i 1}, i=1,2\right)$, both sides would be willing to settle only if there exists at least one $\lambda$ such that $W_{i}^{s} \geq W_{i}^{w}$ for both $i=1,2$. No such $\lambda$ exists if $p=\frac{1}{2} 35$ and

$$
\phi>\frac{1+\lambda}{1+\lambda+\lambda m / 2} \text {. }
$$

Now, in the limiting case when war is not destructive $(\phi=1)$, regardless of the values taken on by the other parameters $(m \in(0,1]$ and $\lambda \in(0,1]>0)$, this condition is always satisfied, implying an unequivocal long-term preference for war. The reasoning here is as follows: When $\phi=1$, the war and settlement payoffs in the first period are identical. Going to war in period $t=1$, however, effectively eliminates one of the opponents in the next period and, with it, the need to arm. In other words, waging war in period $t=1$, when it has no destructive effects, yields both a net total and individual benefit.

More generally, the condition (38) shows that the long-term preference for war is limited by war's destructive effects. In addition, the condition reveals that the players' preference to wage war depends positively on the shadow of the future, $\lambda$. The idea here is as follows: In this dynamic model, war brings benefits to the winner over settlement not only in the current period but in the future. To the extent that the players tend to prefer current consumption relative to future consumption, they would discount those future benefits. But, a higher discount factor, which indicates that the players value the future by more (i.e., discount the future by less) amplifies further the rewards of waging a war today relative to settlement. ${ }^{36}$ The condition (38) shows, in addition, that the players' preference for war depends positively on the effectiveness of the conflict

\footnotetext{
${ }^{34}$ The determination of $\delta\left(G_{11}, G_{21}\right)$ takes as given the share received by side 1 in period $t=2$, $\delta^{e}=\delta\left(G_{12}, G_{22}\right)=\phi p\left(G_{12}, G_{22}\right)+\frac{1}{2}(1-\phi)$, which we already found when we solved for the solutions of the period $t=2$ sub-game, under the assumption that the parties settle in period $t=1: \delta\left(G_{12}^{*}, G_{22}^{*}\right)=\frac{1}{2}$.

${ }^{35}$ As shown below and as was the case in the one-period model, $p=\frac{1}{2}$ always holds in equilibrium. When $p \neq \frac{1}{2}$ the conditions for finding such an $\lambda$ are even more stringent.

${ }^{36}$ We would obtain a similar effect if we were to extend the time horizon of the model, to make the shadow of the future even more important.
} 
technology, $m$. The intuition here is that a more effective conflict technology induces more guns production under settlement as can be seen in (32), and magnifies the potential gains from eliminating one's opponent and not having to arm at all in the second period. Thus, both a longer shadow of the future $(\lambda)$ and a more effective conflict technology $(m)$ make each party more tolerant of war's destructive effects.

Although the destructive effects of war give the players a short-term incentive to settle, in an anarchic setting where writing long-term contracts on arms is not possible, the importance of the future and the compounding rewards of war enjoyed by the winner can induce the players to choose war over settlement. That is, waging war brings with it not simply the chance of taking all of contested resource that remains after combat, but also the potentially even more appealing prospect of not having an opponent at all in the next period. The decision to fight does not ignore its downside risk - namely, the possibility of defeat and being eliminated in the future or more generally being weakened by the opponent and forced to take a much smaller piece of the pie in the future. Despite this downside risk, when initially the two parties are roughly equal, each side could expect a positive net benefit to fighting, due to the asymmetry fighting implies for the their future relative positions and the consequent reduction in arming it brings. Hence, the choice to wage a war instead of settling can be rationalized without having to appeal to misperceptions, or incomplete information about the other side's preferences or capabilities.

\section{Trade, insecurity, and conflict}

Thus far, in each party's choice we have emphasized the trade-off between production and appropriation. Another way of making a living according to traditional economic analysis, however, is trade. That analysis is based on the assumption of perfectly secure endowments and perfect enforcement of these secure endowments. A key, then, to bringing in conflict into the study of trade is to relax that assumption and allow for imperfect or costly enforcement of property rights. Can trade be impeded by insecurity and the potential for conflict? Can restrictions on exchange, subsidies, taxes, land reforms that re-allocate initial endowments ever be (constrained-)efficient in the presence of appropriation and conflict costs? Can autarky ever be superior to free trade under similar conditions? And getting close today's world, is globalization always beneficial in the presence of insecurity?

We will explore such questions in this section. The topic, once one confronts it with the right framework (which we believe we do here), easily reveals itself to be of immense

empirical and historical significance, which unfortunately and curiously has been largely neglected by economists. In the short overview here, we will examine two settings and 
themes. First, we consider the case in which all tradeable goods are insecure, and each party has the choice between secure but less productive autarky versus insecure but more remunerative production for trade. Second, in the case of a model with an insecure resource, we explore the possibility that various restrictions of exchange and other measures viewed as inefficient in a first-best world can be efficient responses when the costs of conflict are taken into account. In that subsection we will touch upon substantive issues as varied as wage subsidies, land reform, and the effects of globalization in the presence of conflict.

\subsection{Secure autarky vs. insecure exchange}

If parties expect to trade, but do not have completely secure possession of the goods they expect to trade, then they must take measures to guard against the theft of those goods by others. We suppose that they do so by arming. If, however, the cost of arming or more generally defense is sufficiently high, they might choose not to participate in the market, and refrain from trade.

To fix ideas we examine a modest extension of the model in section 3.2. Suppose that, on top of the opportunities shown in (12) to produce guns $\left(G_{i}\right)$ and butter $\left(X_{i}\right)$, each player can produce $Y_{i}$, an inferior substitute for butter (say, margarine or just "leisure"). While inferior to butter, this consumption good is assumed to be immune to capture by the opponent. The resource constraint with identical parties $\left(R_{i}=R\right.$ and $\beta_{i}=1$ for both $i^{\prime} s$ ) can be expressed as follows:

$$
R=G_{i}+X_{i}+Y_{i} / \gamma, \quad i=1,2,
$$

where, to express the inferiority of $Y$ to $X$, we have $\gamma<1$. We can think of the total quantity of butter $\left(\bar{B} \equiv F\left(X_{1}, X_{2}\right)=2 R-G_{1}-G_{2}\right)$ as requiring the collaboration of, or an "exchange" between, the two parties so that both parties need to produce a positive quantity of butter for either party to be able to consume any quantity of it. ${ }^{37}$ In a standard neoclassical world with perfect enforcement of property rights, where each party could reap the fruits of its own contribution to butter, there would be neither a need for guns nor an incentive to produce the inferior good, margarine. In this ideal case, each party would produce, and keep for its own consumption, $R$ units of butter. We will refer to such outcomes as "Nirvana" or "no-conflict" outcomes.

With guns determining the distribution of butter and with margarine production

\footnotetext{
${ }^{37}$ Of course, the main point of our example here would be reinforced, and be more convincing, with a more general function, $F\left(X_{1}, X_{2}\right)$, that allows for complementarity, but at considerably higher analytical cost.
} 
being secure, party $i$ can expect the following payoff:

$$
V_{i}\left(G_{1}, G_{2}, Y_{1}, Y_{2}\right)=p_{i}\left(G_{1}, G_{2}\right)\left(2 R-G_{1}-G_{2}\right)+\gamma Y_{i}, \quad i=1,2 .
$$

In this setting, one of two qualitatively different outcomes can emerge in equilibrium:

(i) Autarky. Both parties produce only margarine: $Y^{*}=R$, thus implying $G^{*}=0$ and $X^{*}=0$. The payoffs in this symmetric equilibrium are $V_{i}^{*}=V^{*}=\gamma R$ $i=1,2$. Note that this is always a possible outcome, since both parties need to produce butter in order for either to consume any butter. ${ }^{38}$ That is, given one party produces only margarine, the other party's best response it to produce only margarine as well. But, when $\gamma>\frac{1}{m+1}$, this outcome is the unique equilibrium.

(ii) Exchange. Both parties produce positive quantities of guns and butter as in the equilibrium of subsection 3.2.1, $G_{i}^{*}=G^{*}=\frac{m}{m+1} R$ and $X_{i}^{*}=X^{*}=\frac{1}{m+1} R i=1,2$, but no margarine, $Y_{i}^{*}=0 \quad i=1,2$. In this equilibrium, which emerges only when $\gamma \leq \frac{1}{m+1}$, the payoffs are $V_{i}^{*}=V^{*} \frac{1}{m+1} R, i=1,2$.

The second type of equilibrium is the one in which there is exchange but it requires each side to have guns as back-up. To have such an equilibrium, though, requires that (i) autarky is sufficiently unproductive ( $\gamma$ is low enough) and (ii) conflict is not too effective ( $m$ is low enough). Otherwise, the only equilibrium is when each side engages in autarkic production and no exchange takes place. However, even when the conditions exist for an exchange equilibrium, it is not necessary for it to be implemented in practice, for autarky is always an equilibrium and, depending on the values of the various parameters, it could be the risk-dominant equilibrium.

Both types of equilibria of course yield payoffs lower than those of the Nirvana outcome with perfectly secure property rights. They are also consistent with much of history and this simple model helps us understand how traders were often indistinguishable from warriors, or at least that traders had to buy the protection of warriors. The European explorers of the fifteenth and sixteenth centuries who stumbled into the Americas or opened the way to the East around the Cape of Good Hope were hoping to discover riches that could come from plunder, from trade or both. To do so, they did have to have an ample supply of guns. The tendency for long-distance traders to be heavily armed, or for plunderers to engage in commerce on the side, has been hardly unique to the European explorers, however. The Classical Athenians, the Vikings, the Russians,

\footnotetext{
${ }^{38}$ As suggested above, the same sort of result would obtain if we were to replace this assumption and the simple, linear specification for the total quantity of butter, with a more general functional form, $F\left(X_{1}, X_{2}\right)$, that allows for complementarity between $X_{1}$ and $X_{2}$.
} 
the Genovese and the Venetians, the English and the Dutch East India companies all engaged in both trade and war. In other areas, Bedouins from the desert had plundered and engaged in long-distance trade before the advent of Islam, whereas afterwards Islam itself spread through the proselytizing zeal of merchant-warriors. And, the Chinese empire engaged in massive naval expeditions to East Africa and perhaps beyond decades earlier than the much less impressive expeditions of the European explorers.

To be sure, the rationale for the possible absence of exchange is not simply, as has been emphasized, for example, in Dixit's (2004) recent influential synthesis, that the other party will cheat, either by not paying or by not delivering the promised goods. The rationale here is based instead on the costly measures that the parties are induced to take to avoid being the victims of such cheating. That is to say, the costs of enforcing trade (with guns) could be quite high. This analytically and conceptually distinct reason for the difficulties with exchange has been explored by Rider (1993), Anderton, Anderton, and Carter (1999), Hausken (2004), and Anderson and Marcouiller (2005). These papers present analyses, typically based on models that are more sophisticated than the one presented above, of a variety of factors that affect the emergence of exchange or its absence.

\subsection{Insecure resources, trade restrictions and other market interventions}

Instead of trade itself being insecure, insecurity and contestation of particular resources that are inputs in production is another form of insecurity. Such insecurity has been historically common, and continues to be prevalent today, both across and within countries. Oil, diamonds, and fresh water are examples of contested resources that have received attention lately [see Klare (2001)]. The oil of the Caspian Sea is not simply contested by the governments of the countries that surround it, but by the governments of countries and by private interests well beyond its shores as well as by various private interests within each of the surrounding countries. Here, we are interested in exploring the effects of the tradeability of such resources. Though tradeability confers the classical gains from trade, it can be expected to induce different-possibly higher-levels of arming. That is, to assess the effects of trade, we need to compare the gains from trade against the (possibly) excess levels of arming that trade may induce.

We illustrate the main ideas using a simplified version of the framework of Skaperdas and Syropoulos (2001) for the case of international conflicts and a simplified version of the framework in Garfinkel, Skaperdas, and Syropoulos (2005) for the case of domestic conflicts. Consider as before two parties that can be, depending on the context, countries, groups or individuals. Suppose there are two factors of production, land and labor. The 
parties hold no secure claims to land. That is to say, all available land, denoted by $T_{o}$, is contested. Each party $i$, however, has a secure endowment of $R$ units of labor, which can be transformed, on a one-to-one basis, into guns or used in conjunction with land to produce the final good valued for consumption. In keeping with the example we have used throughout this chapter, we suppose that this good is "butter," $B$. The following Cobb-Douglas function describes the production of output, $B$, given any input quantities of land $T$ and labor $L$ :

$$
B=T^{\alpha} L^{1-\alpha} \text { where } \alpha \in(0,1) .
$$

The timing of actions is as follows:

Stage 1 Each party $i$ chooses its allocation of labor to the production of guns, $G_{i}$ $i=1,2$, leaving $R-G_{i}$ for the production of butter or trade. The two parties make their choices simultaneously.

Stage 2 Given the choices of guns and the technology of conflict as described in (3) with $m=1$, the contested land is divided according to the winning probabilities. At this point, party $i$ 's (new) endowment consists of $p_{i}\left(G_{1}, G_{2}\right) T_{o}$ units of secure land and $R-G_{i}$ remaining units of labor.

Stage 3 These new endowments can be traded domestically or, depending on the trade regime, internationally. Then, given the new quantities of inputs held, each party $i$ produces butter according to (41). Each party aims to maximize its own production of butter.

Assume, for convenience, that the two parties treat the prices of land, labor, and guns as fixed. Taking labor - and guns too, since they are produced on a one-to-one basis from labor, - as the numeraire, let $\pi_{i T}$ denote the relative price of land measured in units of labor, butter, or guns relevant for party $i$. Under free trade, this price is given by world markets. Under autarky, it is determined endogenously by the appropriate domestic market-clearing condition. Given $\pi_{i T}$ as determined in either trade regime, the value of each party's $i$ 's endowment at the beginning of stage 3 , following the division of $T_{o}$ under the threat of conflict in stage 2 , can be written as

$$
\pi_{i T} T_{i}+L_{i}=\pi_{i T} p_{i}\left(G_{1}, G_{2}\right) T_{o}+R-G_{i}
$$

Note how this value depends on the amount of guns chosen by both parties.

As can one can verify, the solution to each party $i$ 's third-stage optimization problem of choosing $T_{i}$ and $L_{i}$ to maximize (41) subject to (42) given the gun choices made in 
stage 1 , yields the following value functions:

$$
V_{i}\left(G_{1}, G_{2} ; \pi_{i T}\right)=\eta\left(\pi_{i T}\right)\left[\pi_{i T} p_{i}\left(G_{1}, G_{2}\right) T_{o}+R-G_{i}\right] \quad i=1,2,
$$

where $\eta\left(\pi_{i T}\right) \equiv(1-\alpha)^{1-\alpha}\left[\alpha / \pi_{i T}\right]^{\alpha}$ denotes the marginal utility of income. With these value functions, which reflect the parties' optimizing third-stage choices, given their firststage guns choices, we now turn to study those first-stage choices under autarky and free trade, whereby we can explore the implications of the two trading regimes for arming and welfare.

\subsubsection{Outcomes under autarky}

When barriers prevent trade across national borders, each party $i$ in stage 1 chooses $G_{i}$ to maximize its respective payoff, $V_{i}^{T}\left(G_{1}, G_{2} ; \pi_{i T}\right)$, shown in (43) with $\pi_{i T}=\pi_{i T}^{A}$ which is taken as given, subject to the conflict technology shown in (3) with $m=1$ and the labor resource constraint $G_{i} \leq R$.

The specific market-clearing conditions that determine $\pi_{i T}^{A}$ depend on whether the parties are countries (engaged in interstate conflict) or adversaries within a single country (engaged in domestic conflict). In the former case, the autarkic price for each party (or country) $i$ would be determined endogenously as a function of the party's respective labor and land endowments: $\pi_{i T}^{A}=\frac{\alpha}{1-\alpha}\left[R-G_{i}\right] / T_{i}$, which would be identical for $i=1,2$ given our symmetry assumptions. When the parties are adversaries within a single country, the possibility of trade between them implies the autarkic price is determined endogenously by an aggregate domestic, market-clearing condition that is common to them: $\pi_{T}^{A}=\frac{\alpha}{1-\alpha}\left[2 R-G_{1}-G_{2}\right] / T_{o}$. Note, however, under our deterministic interpretation of the conflict technology - i.e., where $T_{o}$ is divided according to the parties' winning probabilities, - ex ante symmetry translates into ex post symmetry, such that no trade between domestic groups actually takes place under autarky. Accordingly, the two market-clearing solutions shown above yield the same equilibrium value for the autarkic price, as shown below.

The first-order condition to each party $i$ 's optimization problem in the absence of international trade is given by:

$$
\frac{\partial V_{i}^{A}}{\partial G_{i}}=\eta\left(\pi_{i T}^{A}\right)\left[\pi_{i T}^{A} T_{o} \frac{\partial p_{i}}{\partial G_{i}}-1\right]=0 \quad i=1,2 .
$$

where the marginal effect of party $i$ 's guns choice on its share of land is shown in (9) with $m=1$. These conditions and either solution for $\pi_{i T}^{A}$-either that which applies to interstate conflict or that which applies to intrastate conflict-imply a unique interior 
symmetric solution for guns under autarky, $G_{i}^{A}$ :

$$
\begin{aligned}
G_{i}^{A *}=G^{A *} & =\frac{\alpha}{2-\alpha} R, \quad i=1,2, \\
\text { with } \pi_{T}^{A *} & =\frac{4 \alpha}{2-\alpha} \frac{R}{T_{o}}
\end{aligned}
$$

The optimizing guns choice for each party is proportional to its labor endowment, $R$, and also positively related to $\alpha$, which measures the importance of land in the production of butter.

\subsubsection{Outcomes under trade}

When the barriers to trade are removed, each party $i$ in stage 1 chooses $G_{i}$, subject to the resource constraint $G_{i} \leq R$, to maximize its respective payoff as shown in (43), where $\pi_{i T}=\pi_{T}$, which is given in world markets. The first-order conditions to this problem for $i=1,2$, given by

$$
\frac{\partial V_{i}^{T}}{\partial G_{i}}=\eta\left(\pi_{T}\right)\left[\pi_{T} \frac{\partial p_{i}}{\partial G_{i}} T_{o}-1\right]=0 \quad i=1,2,
$$

with (9), are essentially the same as the first-order conditions $(i=1,2)$ to the analogous

problem under autarky (44). But, these conditions, in which $\pi_{T}$ is exogenously given, imply the following equilibrium choices for guns:

$$
G_{i}^{T *}=G^{T *}=\frac{1}{4} \pi_{T} T_{o}, \quad i=1,2 .
$$

Note how the optimizing choice of guns under trade is increasing in the value of the contested resource, $\pi_{T} T_{o}$, whereas the equilibrium choice of guns under autarky $G^{A *}$ (45a) is not related at all to the contested resource but instead to the secure resource, $R$, and the parameter that indicates its relative importance in the production of butter. Thus, the incentives to arm in the two regimes are quite different. These qualitative differences, in turn, imply that the incentives to arm under trade tend to be greater than those under autarky when (i) the endowment of land is larger relative to that of labor $\left(T_{o} / R\right)$, (ii) when the price of land is larger relative to labor $\left(\pi_{T}\right)$, and (iii) when land is less important in production $(\alpha)$.

\subsubsection{The relative appeal of free trade}

When does trade induce a greater production of guns, and are the added costs of conflict in this case sufficiently large to swamp the gains from trade relative to autarky? To answer these questions, we now compare equilibrium welfare under the two regimes. 
Combining the solution for guns (45a) and the market-clearing price (45b) with the payoff function (43), we can find the equilibrium payoff obtained by each party $i$ under autarky, $V_{i}^{A *}$ :

$$
V_{i}^{A *}=V^{A *}=\left[\frac{1}{2}\right]^{\alpha}\left[\frac{2(1-\alpha)}{2-\alpha}\right]^{1-\alpha} T_{o}^{\alpha} R^{1-\alpha} \quad i=1,2,
$$

Similarly, combining (47) with (43) gives us the parties' equilibrium payoffs under trade, $V_{i}^{T *}\left(\pi_{T}\right)$ :

$$
V_{i}^{T *}\left(\pi_{T}\right)=V^{T *}\left(\pi_{T}\right)=\eta\left(\pi_{T}\right)\left[\frac{1}{4} \pi_{T} T_{o}+R\right], \quad i=1,2 .
$$

These equilibrium payoffs, like those obtained under the conventional assumption that all resources are secure, can be shown to be strictly quasi-convex in the price of land, $\pi_{T}$, reaching a minimum at a certain price, $\pi_{T}^{\min }$. As is well known, in the case that all resources are secure so that there is neither interstate nor intrastate conflict, this minimum price equals the autarkic price. However, where resources are insecure, this critical price is strictly greater than the autarkic price, $\pi_{T}^{A *}{ }^{39}$ Furthermore, given the strict quasi-convexity of $V^{T *}\left(\pi_{T}\right)$, there exists another price, $\pi_{T}^{\prime}>\pi_{T}^{\min }$ defined uniquely by the condition, $V^{T *}\left(\pi_{T}^{A *}\right)=V^{A *}=V^{T *}\left(\pi_{T}^{\prime}\right)$.

With these critical values of $\pi_{T}$, the central results of the model are illustrated in Figure 1. Specifically, this figure depicts the parties' payoffs under free trade $\left(V^{T *}\left(\pi_{T}\right)\right)$ relative to their payoffs under autarky $\left(V^{A *}\right)$ as a function of the relative price of land $\left(\pi_{T}\right)$.

(i) For $\pi_{T}<\pi_{T}^{A}$ and $\pi_{T}>\pi_{T}^{\prime}$, welfare under autarky is higher than welfare under trade $\left(V^{A *}>V^{T *}\left(\pi_{T}\right)\right)$.

(ii) For $\pi_{T}^{A}<\pi_{T}<\pi_{T}^{\prime}$, welfare under trade is higher than welfare under autarky: $\left(V^{T}\left(\pi_{T}\right)>V^{A}\right)$.

The underlying logic here is straightforward: When the international price of land is sufficiently low (i.e., $\pi_{T}<\pi_{T}^{A}$ ), the two parties devote fewer labor resources into guns relative to what they would choose under autarky, since they know that they can use their labor in global markets to buy land cheaply in the third stage. As such, a shift away from the autarkic regime to free trade brings with it not only the familiar gains from trade, but also a reduction in the cost of conflict. When the price equals the autarkic price, $\pi_{T}=\pi_{T}^{A}$, the gains from trade are zero and the costs of conflict under autarky are identical to those under trade. But, when the international price of the contested

\footnotetext{
${ }^{39} \mathrm{Using}(49)$, one can easily confirm that $\pi_{T}^{\min }=\frac{4 \alpha}{1-\alpha} R / T_{o}>\pi_{T}^{A *}=\frac{4 \alpha}{2-\alpha} R / T_{o}$.
} 
resource is higher than its autarkic price, $\pi_{T}>\pi_{T}^{A}$, the stakes of the conflict are higher, thereby inducing the parties to allocate more labor resources to guns under the trade regime relative to the autarkic regime, and the additional cost of conflict more than offsets the gains from trade. In this case, a shift from autarky to trade induces a welfare loss. Only when the price of land is sufficiently high (i.e., , $\pi_{T}>\pi_{T}^{\prime}$ ) will the gains from trade again be greater than the additional costs of guns under trade.

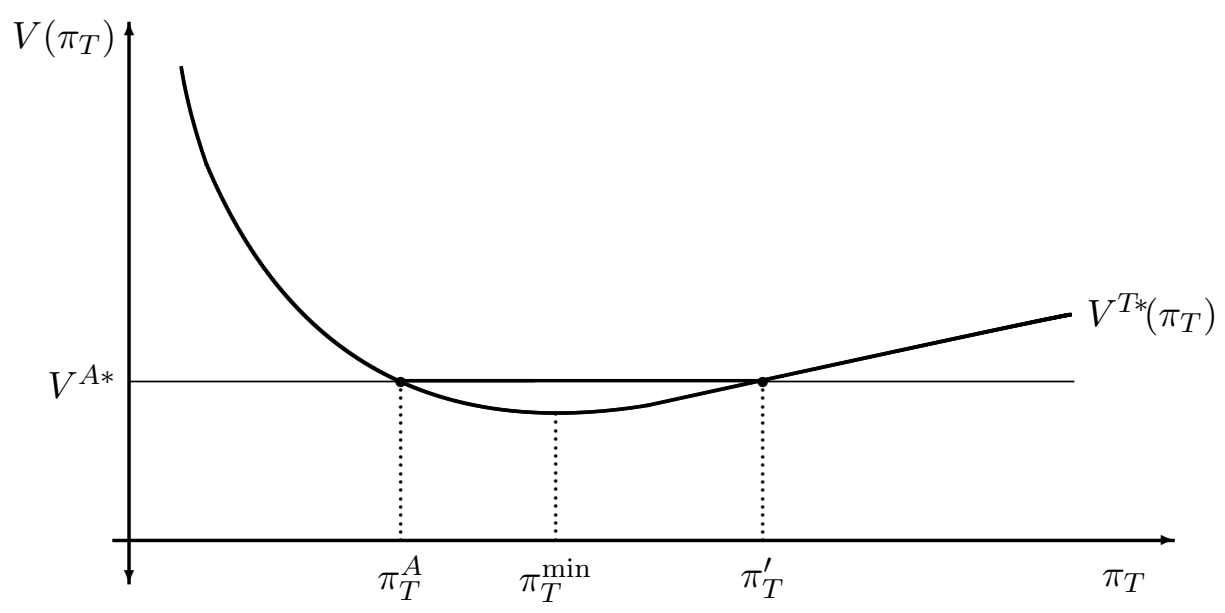

Figure 1: Free trade vs autarchy in the presence of conflict

Thus, trade can be welfare-reducing in the presence of conflict over valuable resources. The particular assumption of price-taking behavior is made for convenience only and can easily be relaxed without changing the main findings. Skaperdas and Syropoulos (2002), for example, allow for bargaining over the price of land, whereas Skaperdas and Syropoulos (1996b) allow for influence on the terms of trade. By the same token, the findings do not hinge on the particular way in which conflict has been modelled here. Findlay and Amin (2000), for instance, consider a trade model in which security is modelled as a public good and is increasing in one country's defense expenditures and decreasing in the defense expenditures of the another country. They similarly find that the gains from trade can be outweighed by the higher defense costs brought about by trade.

\subsubsection{Other implications}

As should be clear by now, the model we have just analyzed can apply to interstate as well as intrastate conflicts with minimal modifications. Interstate conflicts had been frequent and very costly up to World War II. World War I, in particular, took place just after the first big era of globalization, which was also an era of intense competition for 
colonies and resources between the Great powers. Since World War II, however, while the frequency of interstate wars has fallen, civil wars have increased in frequency. Indeed, most of the carnage and, arguably, much economic stagnation and even retrogression since World War II can be attributed civil wars [see Collier et. al. (2003)].

The approach we have taken here also provides an explanation for the "natural resource curse," the tendency of many resource-rich countries to have low or negative rates of growth despite the high prices of their exports. Trade not only makes exporters of contested resources worse off relative to the autarkic regime; it also leaves them vulnerable to declining welfare as increases in the prices for their exports would tend to increase the cost of domestic conflict. As Mehlum et. al. (2006) argue, the key appears to be the security and governance of potentially contestable resources. Countries that have solved the problem of conflict over resources do well, whereas those that have not solved the problem can face declining welfare in the face of the seeming (and fleeting) prosperity that can come from higher oil or other export prices.

The comparison between autarky and complete trade openness is too stark for many contexts. In practice, there are a number of other instruments that countries, groups, or even individual actors could employ to minimize the potentially harmful conflict costs of greater openness to trade and exchange. Authors have argued in different but similar contexts that wage subsidies [Zak (1995) and Grossman (1995)], land reform [Horowitz (1993) and Grossman (1994)], and market interventions in general [Dal Bo and Dal Bo (2004)] can be optimal in the face of various types of conflict, from common crime, to low-level political conflict, to insurrections, civil wars, and interstate wars.

Another way to think of the conflict costs that we have explored in this section in relation to trade and exchange is as a large component of the often-discussed, yet rarely modelled or operationalized, concept of "transaction costs." Taking these costs into account indicates that exchange is neither likely to emerge nor necessarily optimal in a second-best world, and can explain many practices and institutions that would be difficult to comprehend in a world with zero enforcement and conflict costs.

\section{Coalitions and group formation}

The line of research we have reviewed in this chapter has made much progress in advancing our understanding of how conflict manifests itself in many different aspects of our economic lives. This research, however, leaves unanswered many questions about possible "solutions." For example, how can we explain the shift in the nature of conflict that occurred before and after the two world wars? Is this shift one that we can expect to persist or will it eventually reverse itself? Furthermore, why have only some countries been able to solve the problems of security and governance? While it might be overly 
optimistic or pretentious to believe that the approach adopted here could offer any useful insights into such important questions, it seems reasonable to suppose that a good starting point would be to develop a working theory of group formation in the presence of distributional conflict.

In models of conflict, the main parties are typically taken to be unitary actors. While this assumption simplifies matters tremendously, it prevents us from considering other issues that are directly related to the tradeoff between guns and butter. In thinking about why individuals would want to become allies, one might naturally suppose that there are cost-saving advantages that they can realize when they join forces in defending their property against a common enemy [Noh (2002)]. ${ }^{40}$ Or, along similar lines, one could suppose that the impact of pooled efforts is greater than the sum of the effects of individual efforts [Skaperdas (1998)]. In this case, individuals form groups to exploit increasing returns (or super-additivity) in the conflict technology. Of course, the benefits afforded by specialization and increasing returns in production would also provide some basis for group formation.

One could also argue, though, that individual incentives to free-ride would tend to undermine the effectiveness of collective action [Olson (1965)]. For example, where individuals come together in a group to contest some resource, each individual's willingness to contribute to the collective effort would be decreasing in the group's size, since whatever is contested, if won, would have to be shared with the other members, whereas the cost of the contribution is borne privately by the individual. To be sure, this reasoning suggests, at the same time, that the severity of conflict between groups would be diminished by group formation. Nevertheless, one has to acknowledge that, with group formation, there could be an additional source of conflict - namely, over how to allocate whatever the group produces and/or appropriates among the group's members. How does group formation and the ability of groups to manage conflict among their members influence the equilibrium severity of conflict? What sorts of group structures are more conducive to less severe conflict at both the aggregate and the group levels? Are such structures more or less likely to be be stable in equilibrium-i.e., not subject to deviations?

Surprisingly, while there is a relatively large literature on military alliances ${ }^{41}$ and more recently on endogenous group formation, very little has been written on group formation in the context of models of distributional conflict. In this section, we review

\footnotetext{
${ }^{40}$ Also see Sandler (1999). In a related though distinct line of research, Alesina and Spolaore (2006) consider the importance of international conflict in the equilibrium determination of the size and number of the nation-states.

${ }^{41}$ This literature dates back to Olson and Zeckhauser's (1966) seminal paper. See Sandler and Hartley (2001) for an update on the literature.
} 
the relevant literature, highlighting what advances have been made thus far in addressing these and related issues.

\subsection{Stage 1: Inter-group conflict}

We organize our discussion around a simplified model of sequential conflict, which builds on the framework presented in section 3.1, along the lines of Wärneryd (1998) and Esteban and Sákovics (2003). ${ }^{42}$ There are $N$ identical, risk-neutral individuals, $\mathcal{I}=\{1,2, \ldots, N\}$, who participate in a two-stage game. In the first stage, all individuals participate in a winner-take-all contest over a resource $\bar{R}$, which can be consumed directly. They participate either collectively with others or alone, as dictated by the structure of groups, which we take here as given. A group is defined as any subset of the population, $\mathcal{A}_{k} \subseteq \mathcal{I}$, with membership $n_{k} \geq 1$, where $k=1,2, \ldots, A$ and $A$ denotes the total number of groups. For future reference, let the structure of groups be indicated by $S=\left\{n_{1}, n_{2}, \ldots, n_{A}\right\}$, with the groups ordered such that $n_{1} \geq n_{2} \geq n_{3} \cdots \geq n_{A}$. By definition, all individuals belong to a group. However, a group need not include more than one member. Moreover, this framework admits the possibility that everyone comes together to form a single group - the grand coalition: $\mathcal{A}_{1}=\{1,2, \ldots, n\}$.

For any given configuration of groups, each individual $i$, a member of some group $k$, chooses $g_{i}$, her contribution to her group's appropriative effort, $G_{k} \equiv \sum_{i \in \mathcal{A}_{k}} g_{i}$. Then, the probability that group $k$ wins and successfully secures the entire resource, $\bar{R}$, depends on that group's allocation, $G_{k}$, relative to the allocation of all other groups, $G_{-k}$ :

$$
p_{k}\left(G_{k}, G_{-k}\right)=\left\{\begin{array}{cl}
\frac{G_{k}^{m}}{\sum_{j=1}^{A} G_{j}^{m}} & \text { if } \sum_{j=1}^{A} G_{j}^{m}>0 \\
\frac{1}{A} & \text { otherwise }
\end{array}\right.
$$

for all $k$. This specification is based on the symmetric class of conflict technologies for the n-party case, shown in (2), taking the functional form $f(\cdot)=G^{m}$. To capture the special advantages that groups enjoy over individuals in appropriative activities, one could assume, following Skaperdas (1998), super-additivity in $g$ so that $f\left(\sum_{i \in \mathcal{A}_{k}} g_{i}\right)>$ $\sum_{i \in \mathcal{A}_{k}} f\left(g_{i}\right)$, or given $f(\cdot)=G^{m}$ that $m>1 .{ }^{43}$ However, we abstract from any such advantages here, supposing instead that $m=1$. This assumption simplifies the analytics considerably, allowing us to show more clearly how the presence of groups influences the structure of incentives and thus the aggregate intensity of conflict. One important

\footnotetext{
${ }^{42}$ For an extended analysis based on a model that includes production, see Garfinkel (2004a,b).

${ }^{43}$ Skaperdas (1998) shows, in the case where $n=3$, that super-additivity is necessary to make individuals of the group strictly better off than they would be under individual conflict. Noh (2002) obtains a similar result with a slightly different (asymmetric) specification to admit the possibility that groups have some cost advantage in defense.
} 
influence relates to the public-good nature of arming in the contest for $\bar{R}$. In particular, appropriative efforts by different members of a given group are perfect substitutes for one another. Regardless of who provides additional effort, all members enjoy the increased probability of securing the resource it brings to the group.

\subsection{Stage 2: Intra-group conflict}

To fix ideas, suppose that group $k$, with $n_{k}>1$ emerges as the winner of the firststage contest. Individuals not belonging to that group, $i \in \mathcal{A}_{k^{\prime}}$ where $k^{\prime} \neq k$, receive nothing, implying that their first-stage efforts result only in a loss over the two stages. ${ }^{44}$ However, each member of the winning group, $i \in \mathcal{A}_{k}$, goes on to participate in a secondstage contest that determines the distribution of $\bar{R}$ among the group's members. In particular, assume that the share of that resource enjoyed by individual $i \in \mathcal{A}_{k}, \sigma_{i k}$, depends on her effort $s_{i}$, distinct from $g_{i}$, and on the effort by everyone else in her group, $s_{j}$ for $j \neq i \in \mathcal{A}_{k}$ or $s_{-i}$. But her share need not depend entirely on those efforts. More formally, for $n_{k}>1$, individual $i$ 's share is given by

$$
\sigma_{i k}\left(s_{i}, s_{-i}\right)=\left\{\begin{array}{cl}
\frac{1-\mu}{n_{k}}+\frac{\mu s_{i}}{\sum_{j \in \mathcal{A}_{k}} s_{j}} & \text { if } \sum_{j \in \mathcal{A}_{k}} s_{j}>0 \\
\frac{1}{n_{k}} & \text { otherwise, }
\end{array}\right.
$$

where $\mu \in(0,1]$ for all $i \in \mathcal{A}_{k}$. For groups having only one member $\left(n_{k}=1\right)$, there is no internal competition, implying that $s=0$.

The assumption embedded in (51), that members of the group, with $n_{k}>1$, must compete for a share of the prize $(\mu>0)$, departs from the assumption made by otherse.g., Baik and Lee (2001), Noh (2002) and Bloch et. al. (2006), that binding commitments to sharing rules between group members are possible. ${ }^{45}$ However, this general formulation also admits the possibility that social institutions can mediate conflict within the group, and in doing so have implications for intergroup conflict. ${ }^{46}$ In the context of this model, the fraction $1-\mu \geq 0$ measures the effectiveness of existing mechanisms of conflict management to determine the distribution of the group's product without having to rely on the members' current appropriative activities. Put differently, smaller values of $\mu$ would reflect stronger social institutions to effect a less costly resolution of group

\footnotetext{
${ }^{44}$ As specified below, the individual's payoff would be $V_{i k^{\prime}}=-g_{i}$. In other words, the first-stage conflict weakens individuals $i \in \mathcal{A}_{k^{\prime}}$ sufficiently such that it is not possible for them to try to steal the product from the winning group in the second-stage conflict.

${ }^{45}$ In those models, there is essentially no conflict after the first stage.

${ }^{46}$ Of course, this analysis can say nothing about the emergence of such institutions. Genicot and Skaperdas (2002) look specifically at individual investment in conflict management within groups. Related analyses which have considered more specifically the interrelations between democratic political institutions and international conflict, include Garfinkel (1994) and Hess and Orphanides (1995, 2001).
} 
conflict. In what follows, however, we abstract from such influences, and assume that $\mu=1$, not only to keep matters simple but to emphasize the importance of continuing conflict among the members within the winning group. ${ }^{47}$

\subsection{Equilibrium allocations}

Each individual aims to maximize her expected payoff over both stages, given by

$$
V_{i k}^{e}=p_{k}\left(G_{k}, G_{-k}\right)\left[\sigma_{i k}\left(s_{i}, s_{-i}\right) \bar{R}-s_{i}\right]-g_{i},
$$

subject to (50) with $m=1$ and (51) with $\mu=1$, where $G_{k}=\sum_{i \in \mathcal{A}_{k}} g_{i}$, as previously defined. The terms inside the square brackets together represent the payoff to the individual, contingent on her group winning the first-stage contest. Accordingly weighted by the probability that her group wins that contest, this contingent payoff equals her share of the contested resource net of her efforts expended in securing that share. The second term is the utility cost of her contribution made in the first stage to the group's effort in that contest. In choosing her contribution to the group's effort, she will consider not only that cost - a cost she bears alone regardless of whether the group wins or loses the first-stage contest - but also the influence of that contribution on her second-stage choices through the conflict success function. Thus, we follow the strategy adopted earlier in this chapter in accordance with the equilibrium notion of sub-game perfection. That is, we solve the model backwards, starting with the second and final stage.

SECOnd-Stage Outcome. Each individual $i$ belonging to the winning group, $k$, chooses $s_{i}$ to maximize $V_{i k}=\sigma_{i k}\left(s_{i}, s_{-i}\right) \bar{R}-s_{i}-g_{i}$ subject to (51) with $\mu=1$, taking the other group members' choices, $s_{-i}$, as given. The conflict technology (51) with $\mu>0$ generally implies that $s_{i}=0$ for all $i \in \mathcal{A}_{k}$ cannot be an equilibrium outcome. As such, the following condition must be satisfied at an interior optimum:

$$
\frac{\partial V_{i k}^{e}}{\partial s_{i}}=\frac{\sum_{j \neq i \in \mathcal{A}_{k}} s_{j}}{\left[\sum_{j \in \mathcal{A}_{k}} s_{j}\right]^{2}} \bar{R}=1,
$$

for $i \in \mathcal{A}_{k}$. Symmetry of the group's membership, in turn, implies $s_{i}=s>0$. With this result, (51) can be combined with (53), to verify the following Nash equilibrium of the second stage:

$$
\begin{aligned}
s\left(n_{k}\right) & =\frac{n_{k}-1}{n_{k}^{2}} \bar{R} \\
V_{i}\left(n_{k}\right) & =\frac{1}{n_{k}^{2}} \bar{R}-g_{i},
\end{aligned}
$$

\footnotetext{
${ }^{47}$ For a more general analysis based on (51), see Garfinkel (2004b). Also see Niou and Tan (2005) who consider variations on (51) in the case of two alliances.
} 
for $i \in \mathcal{A}_{k}$. In this equilibrium, each member of the winning group enjoys an equal share of the contest prize, $\sigma\left(n_{k}\right)=\frac{1}{n_{k}}$, which is decreasing in the size of the group, $n_{k}$. At the same time, a larger $n_{k}$ implies a greater diversion of effort away from other (presumably valuable) activities towards security. As such, the payoff to the individual is decreasing in the square of the size of the group.

First-Stage outcome. Now consider the first-stage conflict between groups, again with the structure of groups fixed. Each individual $i$ belonging to group $k$ chooses $g_{i}$ to maximize the expected value of (54b), given by

$$
V_{i}^{e}\left(n_{k}\right)=p_{k}\left(G_{k}, G_{-k}\right) \frac{1}{n_{k}^{2}} \bar{R}-g_{i},
$$

where $G_{k}=\sum_{i \in \mathcal{A}_{k}} g_{i}$ subject to (50) with $m=1$. Individuals in all $A$ groups make their decisions simultaneously. The presence of the weight $\frac{1}{n_{k}^{2}}$ on the first term in (55) reflects the negative effects of group size mentioned above - the greater dilution of the prize, $\bar{R}$, and the greater diversion of valuable effort that is positively related to the prize as well. These effects detract from the benefits an individual expects to realize as a result of her contributions to the group's collective effort in the first-stage conflict. The cost to the individual of making such contributions, by contrast, is independent of her group's size. Accordingly, one would expect her choice of $g_{i}$ to be negatively related to the size of her group.

Although the conflict technology (50) implies that $\sum_{j=1}^{A} \sum_{i \in \mathcal{A}_{j}} g_{i}>0$, a fully interior solution is not guaranteed for all configurations of groups when $A>2$. That is to say, the members of one or more groups might choose $g_{i}=0$. But, the stability of a given configuration requires that all groups actively participate in the second-stage conflict. ${ }^{48}$ The analysis to follow, then, considers only such solutions. Accordingly, the individual's choice in the second-stage satisfies the following equality:

$$
\frac{\partial V_{i}^{e}\left(n_{k}\right)}{\partial g_{i}}=\frac{\sum_{i \notin \mathcal{A}_{k}} g_{i}}{\left[\sum_{j=1}^{A} \sum_{i \in \mathcal{A}_{j}} g_{i}\right]^{2}} \frac{\bar{R}}{n_{k}^{2}}=1 .
$$

Maintaining focus on the case of within-group symmetry, ${ }^{49}$ one can find, based on (56), the equilibrium effort put forth by each individual belonging to group $k$ of size $n_{k}$, given

\footnotetext{
${ }^{48}$ The basic idea is that, by participating in the intergroup conflict as a stand-alone group any individual can ensure herself a strictly positive expected payoff, which exceeds the zero payoff obtained by individuals belonging to those groups who do not participate at all. See Garfinkel (2004a).

${ }^{49}$ Since the probability of winning $\bar{R}$ depends on the group's effort $G_{k}$, not just the individual member's effort $g_{i}$ for $i \in \mathcal{A}_{k}$, only total effort by the group is uniquely determined; individual effort, $g_{i}$, is not. Our focus on within-group symmetry seems most natural given the assumption that individual members of the group are identical.
} 
the structure of groups, $S=\left\{n_{1}, n_{2} \ldots, n_{A}\right\}$ :

$$
g\left(n_{k}, S\right)=\frac{A-1}{n_{k} H^{2}}\left[H-(A-1) n_{k}^{2}\right] \bar{R}
$$

for all $k$, where $H \equiv \sum_{j=1}^{A} n_{j}^{2} \cdot{ }^{50}$

For any given group structure with $g_{k}>0$ for all $k$, the solution for $g\left(n_{k}, S\right)$ reveals that the equilibrium effort by the individual members of group $k$ in the intergroup conflict is decreasing in the size of the group, $n_{k}$, as is the total effort by the group, $G_{k}=n_{k} g\left(n_{k}, S\right)$. Hence, the probability of winning the conflict in stage 2 , given by $p\left(n_{k}, S\right)=\frac{1}{H}\left[H-(A-1) n_{k}^{2}\right]$ for $A>1$, is also decreasing in the group size, $n_{k}$. Using this expression for $p\left(n_{k}, S\right),(55)$ and (57), the payoff expected by each individual member of group $k$ at the beginning of stage one, $V^{e}\left(n_{k}, S\right)$, can be written as

$$
V^{e}\left(n_{k}, S\right)=\frac{1}{n_{k}^{2} H^{2}}\left[H-(A-1) n_{k}^{2}\right]\left[H-(A-1) n_{k}\right] \bar{R}
$$

for $k=1,2, \ldots, A$. Not surprisingly then, given any structure of groups, $S$, where $g_{k}>0$ for $k=1,2, \ldots, A$, individuals belonging to larger groups expect a smaller payoff than the payoff expected by those belonging to smaller groups:

$$
V^{e}\left(n_{1}, S\right) \leq V^{e}\left(n_{2}, S\right) \leq \cdots \leq V^{e}\left(n_{A}, S\right)
$$

where by assumption $n_{1} \geq n_{2} \geq \ldots \geq n_{A} .{ }^{51}$ Of course, this ranking says nothing about an individual's incentive to move from one group to another, as it does not account for the effect of the hypothetical move on the efforts levels $g$ by anyone in the stage-two conflict or others' incentive to move in response. However, it should be clear that group formation in this setting generates positive spill-over effects.

\subsection{The level of conflict under different symmetric group structures}

To give just a flavor for how the structure of groups can influence the intensity of conflict, we focus our attention on symmetric structures. In the case where all groups are of equal

\footnotetext{
${ }^{50}$ Specifically, rewrite $(56)$ as $\bar{R}\left(\bar{G}-n_{k} g_{k}\right)=\bar{G}^{2} n_{k}^{2}$, where $\bar{G} \equiv \sum_{j=1}^{A} G_{j}$ denotes the aggregate effort to the first-stage contest and sum over all groups, $k=1,2, \ldots, A$ to obtain $A \bar{R} \bar{G}-\bar{R} \bar{G}=\bar{G}^{2} \sum_{j=1}^{A} n_{j}^{2}$. Simplifying and rearranging shows that, in equilibrium, $\bar{G}=\bar{R}(A-1) / H$, which with the expression above in $g_{k}$ and $\bar{G}$, yields (57). Note our requirement that $g_{k}>0$ for all $k$ is satisfied provided that $H>(A-1) n_{k}^{2}$ holds for $n_{k}=n_{1}$, the number of members in the largest group.

${ }^{51}$ One might conjecture that this ranking depends on the assumption, commonly made in the literature as well as in this paper, of linear costs of effort in the intergroup conflict. Analyzing a model of collective action (with effectively just one layer of conflict), Esteban and Ray (2001) show that, if instead these costs are increasing sufficiently quickly in effort (or money as the case may be), then the group's probability of winning the conflict would be increasing in its size. Nevertheless, they also find that, if the prize is purely private as in the present analysis, the expected payoff to each member would be decreasing in group size.
} 
size $n \geq 1, S \equiv \hat{S}=\{n, \ldots, n\},{ }^{52}$ the solution shown in (57) simplifies to $g(n, \hat{S})=$ $\frac{N-n}{N^{2} n} \bar{R}$. The two extreme symmetric cases of interest are (i) individual conflict where $n=1$ and $A=N$, and (ii) the grand coalition where $n=N$ and $A=1$. In the case of individual conflict, the solution simplifies even further to $g(1, \hat{S})=\frac{N-1}{N^{2}} \bar{R}$. By contrast, when the grand coalition forms the solution is $g(n, \hat{S})=0$. As can easily be confirmed, under alternative, less extreme symmetric structures given $N(=A n), 1 \leq n \leq N$, $g(n, \hat{S})$ is decreasing in $n$ or equivalently increasing in $A$. However, to account for the effect of group structure on the level of conflict, we wish to factor in the conflict that takes place at both stages. In particular, we calculate the expected allocation to the intergroup and intragroup conflict for the representative group and then sum across all $A$ groups. Noting that, for symmetric group structures where $n_{k}=n$ for all $k$, we have that $p(n, N)=\frac{1}{A}=\frac{n}{N}$; and, from (54a), we have $s(n)=\frac{n-1}{n^{2}}$. Bringing these elements together after simplifying yields

$$
A[n g(n, \hat{S})+n p(n, N) s(n)] \frac{1}{A}\left[\frac{N-1}{N}\right] \bar{R}
$$

As this expression shows, given the total number of individuals $N$, the intensity of conflict is decreasing monotonically in the number of groups, $A$. Hence, as we move from a structure with a small number of large groups towards individual conflict, the intensity of conflict decreases.

To be sure, using (58), one can verify that the payoff an individual could expect under a symmetric group structure with $n>1$ is strictly greater than what she can expect under individual conflict (i.e., where $n=1$ ). Nevertheless, this difference is decreasing in the size of each group $(n>1)$ and equals 0 when when $n=N$ or $A=1$. That is to say, the potential gains under the symmetric group structure are decreasing once individuals pair up, and continue to diminish as the groups grow, eventually disappearing - that is, once the group becomes as large as the population, or the grand coalition.

In the context of this simple model, the expected gains from (symmetric) group formation come in the form of a reduction in the severity of conflict over the contestable resource $\bar{R}$ for $1<n<N$. No member of a group with $n>1$ fully internalizes the benefits of her efforts in that conflict and so naturally devotes less effort to it. In the symmetric outcome, everyone else is doing just the same, so that, when compared to the case of individual conflict $(n=1)$, no one has gained an advantage in the conflict over $\bar{R}$ relative to anyone else, yet everyone has a greater chance of winning, $\frac{1}{A}>\frac{1}{N}$. However, as $n>1$ increases and the first-stage conflict between groups weakens, the second-stage conflict over the distribution of $\bar{R}$ within the group intensifies; from an ex ante perspective, the increased costs associated with the intensifying intragroup conflict

\footnotetext{
${ }^{52}$ Ignoring integer problems in the symmetric case, $A=N / n$ and $H=N n$.
} 
exceed the decreased costs associated with the weakening intergroup conflict. As $n$ approaches $N$, the expected gains from group formation go to zero. Of course, the actual outcome under group formation with $n=N$ will differ from that under individual conflict by virtue of the difference in the nature of the conflict in the two outcomes. But, by our assumption that $\mu=1$, the group is no more efficient in resolving conflict than individuals are on their own; therefore, assuming risk neutrality, shifting the entire conflict from one between $A=N$ groups of size $n=1$ to a conflict within $A=1$ group among $n=N$ members has no consequences in terms of expected payoffs. ${ }^{53}$ Still, for $n<N$, the formation of symmetric group on net enhances expected welfare.

\subsection{Requirements of stability and equilibrium group structures}

Would that expected benefit be sufficient to render a symmetric group structure, $\hat{S}$, a stable equilibrium? In the absence of any specific benefits from belonging to a group (i.e., in terms of the conflict or production technologies), it should be fairly obvious that, for any given group structure $S$, each individual would have a large incentive to break away from her own group to form a stand-alone group. The logic here is quite simple. As discussed earlier, each member's incentive to contribute to her own group's collective effort in the first-stage contest over $\bar{R}$ is decreasing in the size of her group. Hence, once having broken away from her group to stand by herself, given the membership of all other groups and that of her former group, any individual would have an increased incentive to put forth some effort in the conflict over $\bar{R}$. At the same time, this deviation would likely decrease the effort made by members of groups not directly affected by the deviation. By forming a stand-alone group, the individual could, then, put herself in a very advantageous position to win the first-stage contest over $\bar{R}$ and she could keep it all for herself.

While this line of reasoning questions the stability of the original structure, one can go a step further to question the stability of the deviation itself, for other individuals too will have an incentive to break away from their respective groups. This is precisely the approach of the noncooperative theory of endogenous coalition structures - see, e.g., Bloch (1996), Chwe (1994), Ray and Vohra (1999), and Yi (1997) - which has recently been applied to group formation in distributional conflict. This approach defines a stable equilibrium by imposing certain internal consistency requirements on possible deviations. One extreme possibility, based on Chwe's (1994) notion of farsighted stability, envisions individuals as looking at the ultimate outcome of a deviation. That is, in their

\footnotetext{
${ }^{53}$ If the members of a group could credibly agree to share the product equally without arming $(s=0)$, the expected payoff under symmetric group formation, given in this case by $V^{e}(n, \hat{S}) \frac{1}{N^{2} n}[N(n-1)+n] X$, would be increasing in $n$, so that the expected gains under group formation relative to individual conflict, $\frac{n-1}{N n} \bar{R}$, would also be increasing in $n$ and be strictly positive when evaluated at $n=N$.
} 
evaluation of the potential gains from a given deviation, they factor in the possibility of all subsequent deviations by others and the resulting impact on expected payoffs. In the context of this model, although any individual would benefit, for example, by leaving her group to form a stand-alone group given the membership of the other groups and her former group, such deviations could ultimately trigger a reversion to individual conflict, leaving everyone, including the original deviator, worse off. Accordingly, such deviations themselves would be deemed unprofitable and, thus, would not pose a threat to the stability of the group structure under consideration. In effect, invoking the notion of farsighted stability expands the opportunities for "cooperation" among individuals who would behave otherwise in a noncooperative way.

A common requirement of stability of the structure of groups in such settings with positive spill-over effects is that the groups be of roughly the same size [Yi (1997)]. Asymmetric structures create larger incentives for deviations particularly for members of the larger groups, and more so when $N$ is small. When there are only 3 individuals, a stable group structure is impossible [Esteban and Sákovics (2003)], unless the alliance enjoys some advantage in the conflict technology [Skaperdas (1998) and Noh (2002)]. More generally, in such settings for any $N$, the failure of the grand coalition to emerge as a stable group structure is common. However, this failure cannot be attributed to the positive spill-over effects of group formation alone. For example, Bloch et al. (2006) predict the emergence of the grand coalition despite the presence of such spill-over effects. In fact, in that model, the grand coalition is the efficient outcome. The reason is because the solution concept, based on Bloch (1996), assumes that the members of a group can commit to an equal sharing rule of whatever they win, thereby abstracting from the intragroup conflict all together. By contrast, when resolving the conflict between members within a group is just as costly as resolving conflict between any other two individuals, smaller groups are more efficient [Garfinkel (2004a)]. Even when one supposes that groups have an advantage in conflict management $(\mu<1)$, there remains a tendency for structures with smaller groups to yield greater expected payoffs for all [Garfinkel (2004b)]. Though the grand alliance could be stable when groups are better able to manage conflict $(\mu<1)$, there are other structures that strictly dominate it from everyone's perspective.

Because scholars have only begun to study group formation and its effects on conflict and peace, there are many avenues for future research. Of special importance would be the study of conflict management within groups. One might adopt a dynamic approach, supposing that the survival of groups over time requires the creation and maintenance of "norms" and institutions that would allow the alliance members to effect a more "peace- 
ful" distribution of output at a lower cost. ${ }^{54}$ In addition, the literature has paid scant attention to asymmetries. Yet, the heterogeneity of individuals raises some important and interesting issues about the composition of alliances and about resolving conflicts therein, provided that a stable structure exists at all.

\section{Dynamics and growth}

Up to this point, section 5.2 is the only place in which we have explicitly examined dynamic issues. Page constraints preclude us from developing a model in which we could examine most of the issues that have been analyzed in the literature. Instead, the following paragraphs summarize some of the central themes. ${ }^{55}$

The costs of CONFLICT OVER TIME REDUCE WELFARE COMPARED TO THE CASE Without CONFLICT. This finding, which is obvious, is present in all of the papers in this area, but is virtually absent from other models of growth that have dominated thinking in this area. Similarly, research on economic development has largely overlooked the costs of conflict and more generally the costs of unproductive activities [on which Sturzenegger and Tommasi (1994) and Barelli and Pessoa (2004) have focused]. This omission is rather astounding given the obvious empirical importance of these costs, which has been recently corroborated by a World Bank study [Collier, et. al., (2003)] and the empirical analysis of Hess (2003). ${ }^{56}$

The InCEnTIVES For PROduCtive INNOVATION ARE SEVERELY REDUCED IN THE PRESENCE OF CONFLICT. Baumol (1990) has provided an intuitive discussion of the importance of secure property rights for productive innovation to flourish. But one can go beyond the basic intuition with the use of appropriate modelling to develop sharp insights. In particular, building on the result based on the benchmark model of section 3.2, Gonzales (2005) demonstrates that, where property is insufficiently insecure, an economic agent might choose not to adopt superior technologies (i.e., those with higher $\beta_{i}$ 's). The reason is not simply because the returns from innovation are expected to be partially expropriated. There is, in addition, a strategic element at play here. That

\footnotetext{
${ }^{54}$ See Genicot and Skaperdas (2002) who model conflict management as an investment decision in a dynamic setting.

${ }^{55}$ The interested reader should consult the relevant references, including Sturzenegger and Tommasi (1994), Hirshleifer (1995a), Zak (1995), Grossman and Kim (1996), Lee and Skaperdas (1998), Barelli and Pessoa (2004), and Gonzalez (2005, 2006).

${ }^{56} \operatorname{Hess}(2003)$, for example, estimates the welfare costs of conflict coming from its effects on consumption alone for 147 countries spanning the period 1960-1992 to be on average 8 percent of steady-state consumption. For some countries, the effect is lower (e.g., 3.2 percent for the United States), but the effect for others, especially the lower income countries, the estimated effect is considerably higher (e.g., 65 percent in Iraq and 40.5 percent in Angola).
} 
is, the adoption of new technologies by one agent would be expected to induce greater relative guns production by the other agents, thereby placing the innovating agent in a disadvantaged position. Thus, even when superior technologies are available at zero cost, the effect of such innovations to make one more vulnerable to appropriation can lead to their rejection in favor of inferior technologies, an outcome that Gonzalez reasonably argues was relevant to many periods in history.

Productive Versus appropriative CAPItal aCCUmulation. The tradeoff between production and appropriation exists not only for outputs with short-term durability. After all, guns typically last a number of years, as so do barracks, fortifications, or siege machines. Such objects can be considered an alternative form of capital, one that is non-productive and which we can call "appropriative" or "enforcive." It could even be argued that for much of history since the agricultural revolution, this type of capital has been quantitatively more important and technologically more sophisticated than ordinary productive capital. Certainly the technology of many castles and siege machines was far more advanced than anything that was available for civilian, material use. The same can be said for the organizational efficiency of standing armies, as no equivalent organizations existed in civilian affairs. Lee and Skaperdas (1998) explore this theme, in a setting where investments in appropriative capital compete with those in productive capital, finding that long-run economic performance can be hindered; and, as with technological choice, this effect can be expected to be dramatic. Thus, differences in governance can be expected to induce differences in capital accumulation. Such differences could, then, also account for the phenomenon of (financial, mobile) capital moving from poor countries to rich countries, the opposite movement one would expect under traditional modelling in which property rights are perfectly and costlessly enforced.

Among other themes that have been explored in dynamic models of conflict and appropriation are the effects of initial asymmetries in resource endowments [Sturzenegger and Tommasi (1994)] and of the degree of property rights enforcement [Gonzalez (2006)]. Consistent with the results in the static version of asymmetric contest models, Sturzenegger and Tommasi (1994) find that asymmetries in initial endowments tend to reduce the total resources devoted to appropriation and thus result in enhanced welfare relative to the case of symmetry. Since Sturzenegger and Tommasi's analysis is based on a deterministic model (which is common where structural dynamics are involved), it would be of interest to examine the case in which the technology of conflict has a probabilistic interpretation (i.e., a "winner-take-all-contest") and to suppose that the winner of the contest gains and maintains an advantage in future encounters. ${ }^{57}$ Using

\footnotetext{
${ }^{57}$ Another area of interest is the simultaneous examination of appropriative conflict and open-access resources. Reuveny and Maxwell (2001) have developed such a promising dynamic model. However, dis-
} 
a version of the asymmetric conflict technology in (5) to parameterize the security of property rights, Gonzalez (2006) shows how, at intermediate levels of security, welfare can be lower than when insecurity is low or high. That is, welfare is non-monotonic in the degree of property right security. Thus, one should exercise caution in recommending improved property-rights enforcement, particularly when such improvements are to be made incrementally in middle income countries. At the same time, it would be worthwhile to examine alternative ways of measuring the security of property rightsfor example, by identifying the degree of security by the fraction of one's output that is immune to capture by others.

Only the surface of the dynamic effects of conflict has been scratched. If politics and institutions are important for economic growth, as much recent research suggests, such effects through our dynamic models could further our understanding of what occurs when institutions are imperfect. However, ultimately the bigger question is how institutions and governance themselves evolve to reduce conflict and appropriation. Hirshleifer (1995a) suggests one factor that leads to the "breakdown" of anarchy: a conflict technology that is highly effective so that only one side emerges victorious. What would happen after one side is in charge, though, and presumably creates a monopolistic "state" is another important topic.

\section{Conflict management and the state}

How can conflict be reduced? That is an immensely important question, of course. The recent literature - which also reflects long-standing intellectual traditions in philosophy and the social sciences - describes two ways to reduce conflict . In Hirshleifer's terminology, conflict can be reduced or eliminated through (i) vertical, Hobbesian contracts or through (ii) horizontal, Lockean contracts. The former can be thought of as proprietary, for-profit, hierarchical governance and the latter as contractual mechanisms that are mostly associated with institutions of modern governance. Ultimately both types of governance rely on the strength of the state to impose a monopoly or near-monopoly in the means of violence, but they also reflect two different types of state.

\subsection{Hierarchical governance}

If one party were to defeat all of its adversaries decisively, so that it effectively gains the monopoly of force, then a long-term hierarchical contract could emerge between the winner and the losers. The winner would maintain a force that could put down

tinguishing between deterministic and probabilistic versions of the model necessitates numerical simulations, which do not appear to yield results that are independent of the parameters used in the particular simulations. 
or deter significant uprisings by the losers, the losers would not expend any resources on arming but would have to accept whatever material compensation their position allows while the winner would enjoy the greater material rewards the dominant coercive position confers. The overwhelming part of recorded history has been characterized by such hierarchical governance, with lords, kings, and emperors on top and masses of peasants at the bottom of the hierarchy. In polities where the monopoly of force has been stronger (or the state was stronger), the degree of conflict has appeared to be less severe. However, the historical record does not reveal an overall reduction in conflict associated with hierarchical governance. Rather, there seems to have been a migration to a different level: conflict with other states and internal succession struggles.

Findlay (1990) was, to our knowledge, the first author to model the state explicitly as a "proprietor," to use Grossman and Noh's (1994) characterization, with the motivation of modelling governance in many LDCs. Grossman and Noh (1994) provided a dynamic version of a similar model to examine the effect of the endogeneity of the ruler's survival and therefore the influence of the effective discount factor on economic policies. McGuire and Olson (1996) went further and argued for the possible effectiveness of autocracy in stimulating investment and economic growth, by likening a ruler to a "stationary bandit" who has an "encompassing interest" so as to limit extortionary taxation and, at the same time, provide high levels of public goods.

However, the incentives of a strong ruler with high extractive powers are not as clear cut as that. First, a long time horizon, necessary for the ruler to have an "encompassing interest," is far from being sufficient for the promotion of growth. As Robinson (1997) has argued, many such policies are often at the expense of their rule: promoting trade implies that merchants become richer and perhaps ask for more rights and a share of power; expanding education can make more of the population become increasingly conscious of its subservient status and therefore demand reforms and a change from the status quo; even building roads can make it easier for rebels to reach the capital and drive out the ruler. Stashing a few billions in Switzerland would be better for the ruler. Second, the extractive power of the ruler can be so high that commitment to a non-extortionary tax rate would be very difficult [Moselle and Polak (2001), Konrad and Skaperdas (2005)]. Moreover, the time horizon of rule is shortened, and its uncertainty widened, by challenges to the ruler from within and without.

Overall, though traditional hierarchical rule could reduce conflict and provide other public goods, it often recreates the problems of conflict at a higher and more organized level. Indeed, tempted by the possible rents that can be extracted from their subjects, rulers have fought incessantly with neighboring rulers throughout history. Moreover, the problem of severely asymmetric coercive power between rulers and the ruled did 
not essentially solve many of the inefficiencies associated with conflict. In many ways it displaced the inefficiencies of high arming and destruction due to conflict with those of lower dynamic incentives for innovation and investment that absolutist rule tends to create. There was nobody to guard the guardians against arbitrary exactions. The type of governance that has intermittently appeared throughout history but has gained more ground over the past two centuries provides another model for reducing and managing conflict.

\subsection{Modern governance}

The alternative mechanism to hierarchical domination for the management of conflict is a contractual arrangement among equals. Note that such a contract is not like the settlement agreements that we examined in sections 4 and 5, for those agreements are backed up by the bargaining power conferred by arming. The contracts that we are concerned with here entail partial or complete disarmament. ${ }^{58}$ Since, ultimately, arming is the primary means of enforcement in settings with insecurity, such contracts pose a serious conundrum: How can the contract be enforced when the contract itself is about the means of its enforcement (i.e., arms)?

There is no complete or timeless solution to this conundrum, for someone somewhere is bound to be tempted to break and will eventually break such a contract at some point in time. Modern governance has partially solved the problem through an elaborate system of enforcement that changes the threat points from those that involve actual fighting to others that involve going to judicial courts, to the legislatures, to bureaucratic rulings, to the voters and so on. Separation of powers, checks and balances, the extension of the democratic franchise, the removal of discretion in ruled-based bureaucracies, and other mechanisms of modern states tend to create a wide dispersion of power and the multilateral sanctions that await anybody who attempts the illegitimate use of force.

Once a modern state has consolidated its main institutions, as in the rich countries of the West, it would be extremely difficult to have, say, a military coup. Protests, strikes, riots, other symptoms of social conflict still occur, of course, but organized warfare has virtually disappeared from within the modern state. How this has come about is still largely a mystery — or, a conundrum — but, a number of scholars have begun the immense task of unravelling the mystery.

This research effort is beyond the scope of our review, but we should mention that conflict figures prominently in all examinations of the emergence of modern governance. Long periods of conflict and the threat of continued conflict have underpinned tran-

\footnotetext{
${ }^{58}$ See Esteban and Sákovics (2006) for the derivation of a bargaining solution based on the threat of conflict but with no arming.
} 
sitions to power-sharing arrangements in as varied places and conditions as Medieval Genoa [Greif (1998)], seventeenth-century England [North and Weingast (1989)], the extension of the democratic franchise in the West [Acemoglu and Robinson (2000)], and the transition from apartheid rule in South Africa [Rosendorff (2001)]. The role of conflict in the building of the institutions that facilitated modern economic growth also figures prominently in the survey of recent research in the area by Acemoglu, Johnson, and Robinson (2004). We agree. The mystery of modern governance as well as the mystery of modern economic growth are siblings of the conundrum of the emergence of cooperation out of conflict.

\section{Concluding Remarks}

We have provided an overview of the recent literature on appropriation and conflict that takes an economic perspective. Conflict is a natural consequence of the basic economic assumption of self-interest, yet it had been hardly examined from an economic perspective up until relatively recently. By accounting for conflict and appropriation in ordinary economic settings, we not only help explain issues that are related to conflict per se. We can also develop a better understanding of the sources of economic growth that concerned Haavelmo (1954) more than half a century ago as well as scholars currently working in the area of institutions and development. In closing, we would like to emphasize some of the more surprising and yet important implications of the research that we have reviewed:

- Conflict involves costs that are economically very important, ranging from the valuable resources diverted away from investment and consumption and instead allocated directly to arming and the resources destroyed in conflict to the reduction in trade and in the accumulation of productive capital. Estimates of the various costs by the World Bank [Collier et. al. (2003)] and Hess (2003) are economically significant, especially for low-income countries; the costs of ordinary economic "distortions" pale in comparison. It is thus surprising, if not shocking, that economists have not paid any attention to these costs until very recently.

- The allocation of resources in the presence of conflict has also been shown to be, generally, very different than when conflict is not present or has no costs. Compensation can easily be inversely related to productivity; superior innovations available at zero cost might be rejected; incentives are often skewed in favor of non-productive investment. Thus, assuming compensation to be positively related to marginal productivity or that all investment is productive in settings that involve conflict in empirical research would be inadvisable. 
- Trade in the presence of insecurity can be absent or suboptimal. Parties that face insecurity in trade may very well choose less productive but more secure alternatives and thus forego trade. Those that do choose to trade would have to invest in defending their possessions, thereby leading to the common phenomenon in history of many merchants doubling as warriors. The costs of fighting over insecure resources can also preclude trade all together.

- A long shadow of the future need not facilitate peace. To the contrary, when fighting changes the long-term strategic positions of adversaries, a long-term horizon could very well induce conflict, despite conflict's short-term costs. This is a source of conflict that has been underemphasized compared with other sources like irrationality or asymmetric information.

- Very little is known about how to reduce, let alone eliminate, conflict. However, based on recent research on institutions and economic growth as well as group formation, we suspect that governance plays an important role. Moreover, conflict itself appears to play an important role in the emergence and evolution of governance. Conflict, governance, and economic growth are tied up in ways that economists and other social scientists have only began to tentatively unravel.

\section{References}

Acemoglu, D., S. Johnson, and J.A. Robinson (2004), Institutions as the fundamental cause of long-run growth, unpublished manuscript, Department of Economics, Massachusetts Institute of Technology, Cambridge, MA.

Acemoglu, D. and J.A. Robinson (2000), Why did the West extend the franchise? Democracy, inequality and growth in historical perspective. Quarterly Journal of Economics 115:1167-1199.

Alesina, A. and E. Spolaore (2006), Conflict, defense spending, and the number of nations, European Economic Review 50:91-120.

Anbarci, N., S. Skaperdas, and C. Syropoulos (2002), Comparing bargaining solutions in the shadow of conflict: How norms against threats can have real effects, Journal of Economic Theory 106:1-16.

Anderson, J. and D. Marcouiller (2005), Anarchy and autarky: Endogenous predation as a barrier to trade, International Economic Review 46:189-213.

Anderton, C.H., R.A. Anderton and J.R. Carter (1999), Economic activity in the shadow of conflict, Economic Inquiry 37:166-179. 
Azam, J.-P. and A. Mesnard, (2003), Civil war and the social contract, Public Choice 115:455-475.

Axelrod, R. (1984), The Evolution of Cooperation (Basic Books, New York).

Baik, K.H. and S. Lee (2001), Strategic groups and rent dissipation, Economic Inquiry 39:672-684.

Barelli P. and S.D. Pessoa (2004), Rent-seeking and capital accumulation, unpublished manuscript, Department of Economics, University of Rochester, Rochester, NY.

Baumol, W.J. (1990), Entrpreneurship: Productive, unproductive, and destructive, Journal of Political Economy, 98, 893-921.

Bester, H. and K. Konrad (2004), Delay in contests, European Economic Review 48:1169-1178.

Bester, H. and K. Konrad (2005), Easy targets and the timing of conflict, Journal of Theoretical Politics, 17 (2): 199-215.

Bester, H. and K. Wärneryd (2006), Conflict and the social contract, Scandinavian Journal of Economics, forthcoming.

Blavatsky, P. (2004), Contest success function with the possibility of a draw: Axiomatization, unpublished manuscript, University of Zurich, Switzerland.

Bloch, F. (1996), Sequential formation of coalitions with fixed payoff division, Games and Economic Behavior 14:90-123.

Bloch, F., S. Sánchez-Pagés and R. Soubeyran (2006), When does universal peace prevail? Secession and group formation in conflict, Economics of Governance, 7:329.

Brito, D. and M. Intriligator (1985), Conflict, war and redistribution, American Political Science Review 79:943-57.

Chwe, M.S.Y. (1994), Farsighted coalition stability, Journal of Economic Theory 63:299325.

Clark, D.J. and C. Riis (1998), Contest success functions: An extension, Economic Theory 11:201-204.

Collier, P., V.L. Elliott, H. Hegre, A. Hoeffler, M. Reynal-Querol, N. Sambanis (2003), Breaking the Conflict Trap; Civil War and Development Policy, World Bank Policy Report (Washington, DC: World Bank and Oxford University Press).

Dal Bo, E. and P. Dal Bo (2004), Workers, warriors and criminals: Social conflict in general equilibrium, unpublished manuscript, Haas School of Business, University of California, Berkeley, CA. 
Dixit, A. (2004), Lawlessness and Economics: Alternative Models of Governance (Princeton University Press, Princeton).

Esteban, J.M. and D. Ray (1999), Conflict and distribution, Journal of Economic Theory $87: 379-415$.

Esteban, J.M. and D. Ray (2001), Collective action and group size paradox, American Political Science Review 95:663-672.

Esteban, J.M. and J. Sákovics (2003), Olson vs. Coase: Coalition worth in conflict, Theory and Decision 55:339-357.

Esteban, J.M. and J. Sákovics (2006), A theory of agreements in the shadow of conflict, unpublished manuscript, University of Edinburgh, Edinburgh, UK.

Fearon, J.D. (1995), Rationalist explanations for war, International Organization 49:379414.

Findlay, R. (1990), The new political economy: its explanatory power for the LDCs, Economics and Politics 2:193-221.

Findlay, R. and M. Amin (2000), National security and international trade: a simple general equilibrium model, unpublished manuscript, Department of Economics, Columbia University, New York, NY.

Garfinkel, M.R. (1990), Arming as a strategic investment in a cooperative equilibrium, American Economic Review 80:50-68.

Garfinkel, M.R. (1994), Domestic politics and international conflict, American Economic Review 84:1292-309.

Garfinkel, M.R. (2004a), Stable alliance formation in distributional conflict, European Journal of Political Economy 20:829-852.

Garfinkel, M.R. (2004b), On the stable formation of groups: Managing the conflict within, Conflict Management and Peace Science 21:43-68.

Garfinkel, M.R. and S. Skaperdas (2000), Conflict without misperceptions or incomplete information: how the future matters, Journal of Conflict Resolution 44:793-807.

Garfinkel, M.R., S. Skaperdas, and C. Syropoulos (2005), Globalization and domestic conflict, unpublished manuscript, Department of Economics, University of California, Irvine, CA.

Genicot, G. and S. Skaperdas (2002), Investing in conflict management, Journal of Conflict Resolution 46:154-170.

Gonzalez, F.M. (2005), Insecure property and technological backwardness, Economic Journal 115, 703-721. 
Gonzalez, F.M. (2006), Effective property rights, conflict and growth, Journal of Economic Theory, forthcoming.

Greif, A. (1998), Self-enforcing Political Systems and Economic Growth: Late Medieval Genoa, in R. Bates, A. Greif, M. Levi, and J-L. Rosenthal, eds. Analytic Narratives (Princeton: Princeton University Press).

Grossman, H.I. (1991), A general equilibrium model of insurrections, American Economic Review 81:912-921.

Grossman H. I. (1994), Production, appropriation, and land reform, American Economic Review 84:705-712.

Grossman H. I. (1995), Robin Hood and the redistribution of property income European Journal of Political Economy, 11:399-410.

Grossman H.I. and S.J. Noh (1994), Proprietary public finance and economic welfare, Journal of Public Economics 53:187-204.

Grossman, H.I. and M. Kim (1995), Swords or plowshares? A theory of the security of claims to property, Journal of Political Economy 103:1275-288.

Grossman, H.I. and M. Kim (1996), Predation and accumulation, Journal of Economic Growth 1:333-351.

Haavelmo, T. (1954), A Study in the Theory of Economic Evolution. (North-Holland, Amsterdam).

Hausken, K. (2004), Mutual raiding and the emergence of exchange, Economic Inquiry 42:572-586.

Hess, G.D. (2003), The economic welfare cost of conflict: an empirical assessment, CESifo Working paper no. 852, Munich, Germany.

Hess, G.D. and A. Orphanides (1995), War politics: An economic, rational-voter framework, American Economic Review 85:828-846.

Hess, G.D. and A. Orphanides (2001), War and democracy, Journal of Political 109:776810.

Hirshleifer, J. (1988), The analytics of continuing conflict, Synthese 76:201-33.

Hirshleifer, J. (1989), Conflict and rent-seeking success functions: Ratio vs. difference models of relative success, Public Choice 63:101-112.

Hirshleifer, J. (1991), The paradox of power, Economics and Politics 3:177-200.

Hirshleifer, J. (1995a), Anarchy and its breakdown, Journal of Political Economy 103:26-52. 
Economics of Conflict: An Overview

Hirshleifer, J. (1995b), Theorizing about conflict, in K. Hartley and T. Sandler, eds., Handbook of Defense Economics, Vol.1, 165-189 (North Holland, Amsterdam).

Hirshleifer, J. (2000), The macrotechnology of conflict, Journal of Conflict Resolution, December, 44: 773-792.

Hirshleifer, J. and J. Riley (1992), The Analytics of Uncertainty and Information (Cambridge University Press, New York, NY).

Horowitz, A.W. (1993), Time paths of land reform: A theoretical model of reform dynamics, American Economic Review 83:1003-1010.

Jia, H. (2005), A stochastic derivation of contest success functions, unpublished manuscript, Department of Economics, University of California, Irvine, CA.

Klare, M.T. (2001), Resource Wars: The New Landscape of Global Conflict (Henry Holt and Company, New York, NY).

Konrad, K.A. (2005), Strategy in Contests, (book manuscript in preparation), WZBBerlin, Germany.

Konrad, K.A. and H. Schlesinger (1997), Risk aversion in rent-seeking and rent-augmenting games, Economic Journal 107:1671-1683.

Konrad, K.A. and S. Skaperdas (2005), The Market for Protection and the Origin of the State, unpublished manuscript, Department of Economics, University of California, Irvine, CA.

Lee, J. and S. Skaperdas (1998), Workshops or barracks? Productive versus enforcive investment and economic performance, in M.R. Baye, ed., Advances in Applied Microeconomics, vol. 7 (JAI Press, Greenwich, CT).

Luce, R.D. (1959), Individual Choice Behavior (Wiley, New York, NY).

McBride, M. and S. Skaperdas (2005), Explaining conflict in low-income countries: Incomplete contracting in the shadow of the future, unpublished manuscript, Department of Economics, University of California, Irvine, CA.

McGuire, M. and M. Olson (1996), The economics of autocracy and majority rule: The invisible hand and the use of force, Journal of Economic Literature 34:72-96.

Mehlum, H., K. Moene and R. Torvik (2003), Predator or prey? Parasitic enterprizes in economic development, European Economic Review 47:275-294.

Mehlum, H., K. Moene, and R. Torvik (2006), Institutions and the resource curse, Economic Journal 116:1-20.

Milgrom, P. (1988), Employment contracts, influence activities, and efficient organization design, Journal of Political Economy 96:42-60. 
Moselle, B. and B. Polak (2001), A model of a predatory state, Journal of Law, Economics, and Organization 17:1-33.

Muthoo, A. (1999), Bargaining Theory with Applications (Cambridge University Press, New York, NY).

Neary, H.M. (1997), Equilibrium structure in an economic model of conflict, Economic Inquiry 35:480-94.

Niou, E.M.S. and G. Tan (2005), External threat and collective action, Economic Inquiry 43:519-530.

Nitzan, S. (1994), Modelling rent seeking contests, European Journal of Political Economy 10:41-60.

Noh, S.J. (2002), Resource distribution and stable alliance with endogenous sharing rule, European Journal of Political Economy 18:129-151.

North, D.C. and B. Weingast (1989), Constitutions and commitment: The evolution of institutions governing public choice in seventeenth-century England, Journal of Economic History, 49:803-832.

Olson, M. (1965), The Logic of Collective Action (Harvard University Press, Cambridge, MA).

Olson, M. and R. Zeckhauser (1966), A theory of alliance formation, Review of Economics and Statistics 47:266-279.

Osborne, M.J. and A. Rubinstein (1990), Bargaining and Markets (Academic Press, San Diego, CA).

Powell, R. (1993), Guns, butter, and anarchy, American Political Science Review 87:115132.

Powell, R. (2006), War as a commitment problem, International Organization, 60:169203.

Rajan, R.G. and L. Zingales (2000), The tyranny of inequality, Journal of Public Economics 76:521-558.

Ray, D. and R. Vohra (1999), A theory of endogenous coalition structures, Games and Economic Behavior 26:286-336.

Reuveny, R., and J.W. Maxwell (2001), Conflict and renewable resources. Journal of Conflict Resolution 45:719-742.

Rider, R. (1993), War, pillage, and markets, Public Choice 75:149-156. 
Robinson, J.A. (1997), When is a state predatory?, unpublished manuscript, Department of Economics, University of Southern California, CA.

Rosendorff, B.P. (2001), Choosing democracy: The transition in South Africa, Economics and Politics, 13:1-29

Sánchez-Pagés, S. (2004), The use of conflict as a bargaining tool against unsophisticated opponents, unpublished manuscript, University of Edinburgh, Edinburgh, UK.

Sandler, T. (1999), Alliance formation, alliance expansion, and the core, Journal of Conflict Resolution 43:727-747.

Sandler T. and K. Hartley (2001), Economics of alliances: The lessons for collective action, Journal of Economics Literature 39:869-896.

Schmalensee, R. (1972), The Economics of Advertising, (North-Holland, AmsterdamLondon).

Skaperdas, S. (1991), Conflict and attitudes toward risk, American Economic Review 81:160-64.

Skaperdas, S. (1992), Cooperation, conflict, and power in the absence of property rights, American Economic Review 82:720-739.

Skaperdas, S. (1996), Contest success functions, Economic Theory 7:283-90.

Skaperdas, S. (1998), On the formation of alliances in conflict and contests, Public Choice 96:25-42.

Skaperdas, S. and C. Syropoulos (1996a), Can the shadow of the future harm cooperation?, Journal of Economic Behavior and Organization 29:355-72.

Skaperdas, S. and C. Syropoulos (1996b) Competitive trade with conflict, in M.R. Garfinkel and S. Skaperdas, eds., The Political Economy of Conflict and Appropriation (Cambridge University Press, New York, NY) 73-95.

Skaperdas, S. and C. Syropoulos (1997), The distribution of income in the presence of appropriative activities, Economica, 64:101-17.

Skaperdas, S. and C. Syropoulos (2001), Guns, butter, and openness: on the relationship between security and trade, American Economic Review, Papers and Proceedings 91:353-357.

Skaperdas, S. and C. Syropoulos (2002), Insecure property and the efficiency of exchange, Economic Journal 112:133-146.

Sturzenegger, F. and M. Tommasi (1994), The distribution of political power, the costs of rent-Seeking, and economic growth, Economic Inquiry, 32:236-248. 
Szymanski, S. (2003), The economic design of sporting contests, Journal of Economic Literature 41:1137-1187.

Tullock, G. (1980), Efficient rent seeking, in: J.M. Buchanan, R.D. Tollison, and G. Tullock, eds., Toward a Theory of the Rent Seeking Society (Texas A\&M University Press, College Station, TX) 3-15.

Wärneryd, K. (1998), Distributional conflict and jurisdictional organization. Journal of Public Economics 69:435-450.

Wärneryd, K. (2003), Information in conflicts, Journal of Economic Theory, 110:121136.

Wittman, D. (2000), The wealth and size of nations, Journal of Conflict Resolution 44:868-884.

Yi, S.-S. (1997), Stable coalition structures with externalities, Games and Economic Behavior 20:201-237.

Zak, P.J. (1995), Institutions, property rights and growth, unpublished manuscript, Department of Economics, Claremont Graduate School, Claremont, CA. 